Article

\title{
Bio-Inspired Sustainability Assessment for Building Product Development-Concept and Case Study
}

\author{
Rafael Horn ${ }^{1, *}$, Hanaa Dahy ${ }^{2,3}$, Johannes Gantner ${ }^{1}$, Olga Speck ${ }^{4}$ and Philip Leistner 5 \\ 1 Department of Life Cycle Engineering, Fraunhofer Institute for Building Physics IBP, \\ 70563 Stuttgart, Germany; johannes.gantner@ibp.fraunhofer.de \\ 2 BioMat Department: Bio-Based Materials and Materials Cycles in Architecture, \\ Institute of Building Structures and Structural Design, University of Stuttgart, \\ 70174 Stuttgart, Germany; h.dahy@itke.uni-stuttgart.de \\ 3 Faculty of Engineering, Department of Architecture (FEDA), Ain Shams University, 11517 Cairo, Egypt \\ 4 Plant Biomechanics Group, Botanic Garden, University of Freiburg, 79104 Freiburg, Germany; \\ olga.speck@biologie.uni-freiburg.de \\ 5 Institute for Acoustics and Building Physics, University of Stuttgart, 79569 Stuttgart, Germany; \\ philip.leistner@iabp.uni-stuttgart.de \\ * Correspondence: rafael.horn@ibp.fraunhofer.de; Tel.: +49-711-970-3188
}

Received: 30 November 2017; Accepted: 29 December 2017; Published: 8 January 2018

\begin{abstract}
Technological advancement culminating in a globalized economy has brought tremendous improvements for mankind in manifold respects but comes at the cost of alienation from nature. Human activities nowadays are unsustainable and cause severe damage especially in terms of global depletion and destabilization of natural systems but also harm its own social resources. In this paper, a sustainability assessment method is developed based on a bio-inspired sustainability framework that has been developed in the project TRR 141-C01 "The biomimetic promise". It is aims at regaining the advantages of societal embeddedness in its environment through biological inspiration. The method is developed using a structured approach including requirement specification, description of the inventory models on bio-inspiration and sustainability assessment, creation of a bio-inspired sustainability assessment model and its validation. It is defined as an accompanying assessment for decision support, using a six-fold two-dimensional structure of social, economic and environmental functions and burdens. The method is applied and validated in 6 projects of TRR 141 and its applicability is exemplarily shown by the assessment of "Bio-flexi", a biobased and biodegradable natural fiber reinforced plastic composite for indoor cladding applications. Based on the findings of the application the assessment method itself is proposed to be advanced towards an adaptive structure and a consequent outlook is provided.
\end{abstract}

Keywords: bio-inspiration; sustainability assessment; function; resource; burden; Design for sustainability; life cycle thinking; bio-flexi

\section{Introduction}

The technological and cultural development of mankind includes rapid-growing interconnectivity of markets as a result, culminating in a globalized economy is the main driver for the tremendous improvements that mankind is profiting from in manifold respects. It enabled certain autonomy from the dependence on natural cycles and dealt as one of the main drivers towards what is known as civilization [1]. The Neolithic revolution can be identified as the first step of this emancipation process, offering a way to decouple availability and demand for food in time. Coming along with innovative transportation methods and economic development trade was established which reduced the spatial dependency. Although the resulting human activities already had strong impacts on their 
environments, these remained mainly local and did not affect the global ecosystem as such [2]. With the discovery of fossil energy, the availability of energy underwent a similar process, enabling shifting energy in time and space and thus overcoming spatial dependency. This final step of emancipation from the restrictions of natural cycles facilitated the globalized economy of the modern society. Although providing indisputable advantages in almost every sphere of life for humans, this development comes at a cost of both the alienation of humans from nature itself and of the current global depletion and destabilization of natural systems [1,3]. Regarding the results of men's worldwide activities; a point is reached where potentially irreversible impacts on systems of global relevance are likely to be threatening human life $[4,5]$. Thus, solutions have to be created to address these challenges in a way that allows ongoing societal prosperity.

Over the history of sustainability living nature has played a major role in its understanding and application of frameworks to strive for and oftentimes was referred to as source of inspiration [6-9]. To facilitate the transfer of advantageous aspects from biology to technology, the functions of biological systems deal as fundamental basis for the assessment system structure. Therefore, a methodological approach to assess innovations has been developed through conflating bio-inspiration and sustainability based on the reintegration of basic bio-inspired principles into material systems of humankind. Its goal is to effectively develop sustainable construction products, which requires an adaptive assessment system to accompany product development. This is achieved through the abstraction of basic principles of biological systems on artificial systems and the deriving of a set of indicators and according weighting based on these transposed rules. While the conceptual framework has already been described, its concretization and exemplary application is subject to this work [10,11]. The framework has been put into practice by applying a structured approach to design and specify the elements of the sustainability assessment including their interrelation on a quantitative basis. This assessment system and its development are the core of the publication.

\section{Development of the Assessment System}

The proposed assessment system has been developed following a structured approach. It grounds on the bio-inspired sustainability framework developed and is applied in the Collaborative Research Centre "TRR141: Biological Design and Integrative Structures-Analysis, Simulation and Implementation in Architecture", funded by the German Research Foundation DFG [10]. The framework is inspired by one of the basic principles of living systems, namely the autopoietic model describing self-maintaining through the fulfilling of elementary functions using available resources [12,13]. As the area of application is restricted to the built environment and mainly deals with the development of innovative, bio-derived products, the assessment has been designed for this field and its applicability is restricted to it.

The development of an assessment system usually consists of a consolidation of existing and specifically developed fragments through a scientific approach including a validation of the assessment framework and its underlying calculation scheme. The central underlying existing frameworks applied in this context are bio-inspiration and life cycle based sustainability assessment, coming together through the scientific process of biomimetics. Within the Collaborative Research Center (TRR 141) using an interdisciplinary team of experts is jointly working on the development of bio-inspired innovations for the construction sector aiming among others at sustainability of the solutions. As this requirement is an integral part of the TRR 141, it proves an ideal development and application environment for a Bio-inspired Sustainability Assessment (BiSA) model. The method development is conducted based on the following steps:

I. Requirement specification

II. Initial situation
a. Sustainability
b. Bio-inspiration 
III. Synthesis creation
IV. Application
V. Validation
VI. Adaption

The requirements (I) to the accompanying assessment of bio-inspired product development are defined in Section 2.1. This includes both general requirements for assessment systems and specific requirements concerning sustainability, bio-inspiration and decision support in product development. In Section 2.2 (IIa, sustainability) and Section 2.3 (IIb, biology) the fundamental frameworks are presented focusing on the adaptions to the state of the art that are required and the specifically developed schemes. The BiSA system derived as synthesis from the underlying basic concepts is described in Section 2.4 (III) and applied to a case study in Section 3. Based on this application (IV) the compliance to the requirements are discussed in Section $4(\mathrm{~V})$ and recommendations (VI) are presented in Section 5, giving an insight in the planned adaption and improvement of the assessment.

\subsection{Requirements to a Bio-Inspired Sustainability Assessment}

The development of a comprehensive sustainability assessment model for a targeted development of sustainable products underlies certain requirements in terms of methodology and applicability. The general requirements refer to basic principles for scientific methods such as consistency, comparability, reproducibility and falsifiability [14]. Besides the general requirements that apply for all assessment systems, specific context-related requirements have to be considered for evaluating the assessment system. These are related to decision support systems, sustainability assessment systems and bio-inspired systems [11].

Although mainly focused on the management of decision making processes, there have been several approaches to specify requirements for decision support systems (DSS) in decision theory that provide universal requirements [15-17]. Their common denominator is the emphasis of an adaptive and flexible applicability of DSS. A DSS should therefore also be capable of supporting semi-structured and unstructured decisions, for all levels of decision makers, regardless of their proficiency and throughout all phases of the decision making process [17]. For sustainability assessment systems, the systemic framework shown in Figure 1 is applied [18,19]. It provides a semi-quantitative scale of seven criteria covering the most relevant aspects that are prevailing in scientific literature [20-23]. All criteria are staggered in three levels and providing a scorecard of the assessment system.

The classification of an assessment system as bio-inspired can be described based on the intrinsic system properties of effectivity, adaptability and resilience [10]. Effectivity is defined with regard to the required effort by the practitioner required to generate the desired information yield. As this is an aspect that can only be investigated through practitioner monitoring through application, it requires a minimum number of applied studies with integrated BiSA. The system is classified as adaptive when it offers flexibility and expandability in an indicator and weighting scheme and realizes this through ongoing self-evaluation and adaption. If the assessment model is able to absorb changes in input in terms of reasonable system deflections, it is regarded as being resilient [24].

\subsection{Properties of Sustainability Assessment Methods}

Sustainability can foremost be understood as societal paradigm and its perception as such has potentially a high influence on almost every decision that is taken, starting from everyday decisions up to global politics. Its constructive ambiguity together with its level of abstraction as well as the complexity of cause-action-relation, interconnectivity and multidimensionality are leading to the point that the meaning of the term is commonly changed and shaped due to subjective perceptions [25]. Although sustainability nowadays shows ubiquitous appearance there is still a lack of consensus when it comes to defining detailed concepts going beyond the overall agreement shaped in "Our common future" [26]. The sustainability development goals (SDGs) can be seen as a milestone in the effort of 
consensus finding but still does not offer a comprehensive and quantifiable catalogue of indicators capable of assessing the sustainability especially when it comes to dedicatedly developing sustainable products. Overall the multitude of concepts, interpretations and respective methods and models to assess sustainability gives a hint that the paradigm of sustainability is still evolving and its shape is still to be found [27].

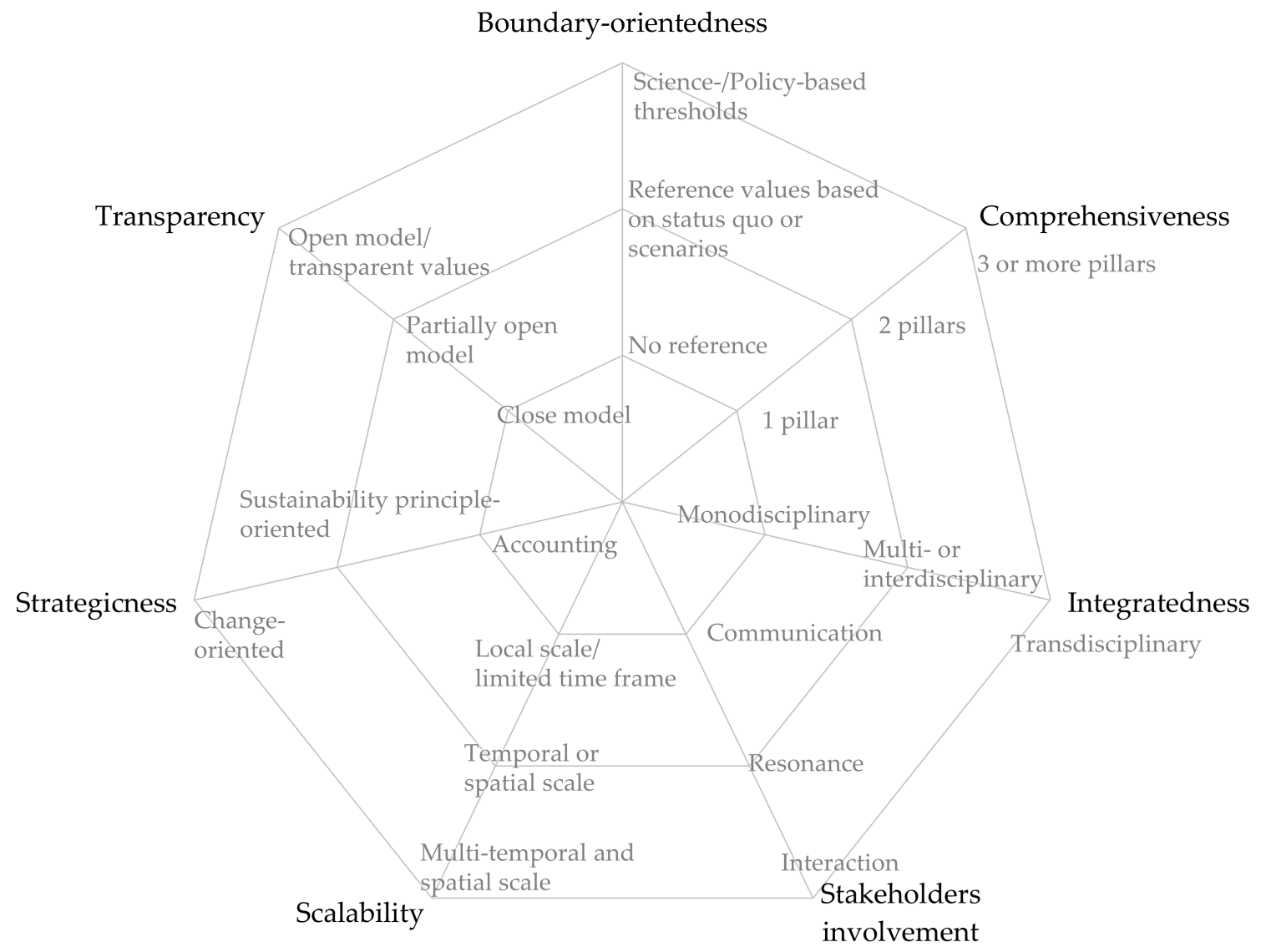

Figure 1. Requirements depicted as spider chart to assess the capability of sustainability assessment methods to address sustainability (adapted from Sala et al. (2015), figure licensed under CC BY NC ND) [19].

In the following, concepts and assessment methods are presented focusing on their consistency and suitability to a quantified assessment of products over their life cycle. While there are numerous concepts available, most are originally restricted to a schematic level and have to be transferred and differentiated to fully apply quantified life cycle thinking and thus provide comparable and specific results on a level that facilitates detailed decision support [28]. The concept of cradle to cradle, for example, is presented as a design framework for sustainable products but offers several inconsistencies when combined with quantified life cycle thinking [29,30]. The same does apply to the concept of natural capitalism, which only monetarizes all environmental resources and is therefore a method for single point creation in Life Cycle Assessment (LCA) than a sustainability concept. If enhanced by human and man-made capital as applied in the triple-bottom-line LCA, all the pillars can be addressed, while still their interpretation is restricted to monetary quantities [31,32].

There are numerous approaches available which are neither consistent nor comparable among each other on a quantitative basis. As the investigation of existing sustainability assessments has been extensively conducted by several recent publications, these are chosen as a basis for the assessment of the research situation [33-35]. Guinée has provided an extensive meta-assessment of Life Cycle 
Sustainability Assessment (LCSA) studies in scientific literature including a comprehensive list of general recommendations and potential improvements that are lacking for existing studies and should be tackled in the LCSA assessment development [35]. Among others, the following key points have been stated: general need for data and methods, especially for social indicators; communication of results; integration of beneficial aspects; avoiding of double counting and inconsistent application. As these points are still unsolved, there is clear evidence for a demand of further methodological development for improved sustainability assessments, dealing with these issues and thus improving both broadness and depth as well as communication [35].

\subsection{Biological Idea Generators for Sustainability Assessment}

Particularly because the described sustainability assessment is inspired by biology and tailored to the construction sector, different concepts of learning from nature are presented and illustrated by means of selected examples from the building sector. Learning from nature is linked with the hope of learning from biological solutions that seem to be optimized in the evolutionary process over the last 3.8 billion years. In principle, three levels of learning from nature can be distinguished: (i) learning from the results, (ii) the processes and (iii) the principles of biological evolution [36]. These three levels have a common systematic approach of knowledge transfer but differ in the type of the transferred knowledge.

The first level of learning from living nature is the study of the form-function relationships of biological role models. Taking into account that even the transfer of an inspiring idea is a conscious process, the transferred inspiration leads to a bio-inspired product. A famous example is the plant-inspired reinforced concrete developed by the French gardener Joseph Monier in 1867 [37]. Based on an inspiration, additional knowledge transfer is possible, such as the transfer of morphology leading to a biomorphic product such as the Crystal Palace, a cast-iron construction built by the gardener Sir Joseph Paxton being inspired by the ribbed leaves of water lilies [38] and the transfer of a functional principle resulting in a biomimetic product [11]. Special attention should be paid to the transfer of a function or in other words the statement that the biological role model and the technical product possess the same function as for example the self-cleaning surfaces of lotus leaves and the façade paint Lotusan ${ }^{\circledR}$ or different functions such as the façade shading system Flectofin ${ }^{\circledR}$ inspired by the pollination mechanisms of the bird-of-paradise flower $[39,40]$. The meaning of function is thereby different whether used in the field of biology or technology. Biological functions are understood in the sense of traits evolved to increase the organism's fitness and contribute to the evolutionary success [41]. In contrast, technical functions are defined in the sense of a specific process, action or task [42]. Examples for the second level of learning from evolutionary processes are the optimization algorithms based on growth rules of trees (Computer Aided Optimization) and bones (Soft Kill Option) and the evolutionary algorithms, which lead to biomimetically optimized products [11]. The third level of learning from nature is based on the principles of biological evolution such as multifunctionality, hierarchy, robustness (fault tolerance), resilience (failure tolerance), redundancy, self-X-functions, adaptation, consistency, modularity, sudden transitions (i.e., leaf drop), gradual transitions, growth, opportunism, metabolism under mild environmental conditions (enzymes) [43] and resource efficiency [8]. In ecology, the term "resources" refers to essential environmental factors that can be subdivided into biotic (e.g., food, host, reproductive partners) and abiotic factors (e.g., space, light, water) [44].

In summary, it can be said that despite the inspiratory flow and knowledge transfer from biology to technology, bio-inspired products are not necessarily sustainable as a side effect. The challenge is that there is no biological model and no method for a straightforward transfer into any model of the paradigm of sustainability. This is due to the fact that living nature itself as a result of biological evolution cannot be comprehensively described through the concept of sustainability. It is a man-made teleological and anthropocentric paradigm with the goal of preserving the status quo for the next generations $[45,46]$. The paradigm of sustainability is of teleological nature and therefore 
to be distinguished from biological systems, where teleology is seen as an insufficient concept to describe reproduction and evolution [47]. In contrast, biological evolution is seen a blind process characterized by the dynamics of evolutionary adaptations on basis of mutation, recombination and selection in an ever-changing environment with the result of multifunctional and optimized structures or processes after several generations [41]. On the one hand, the concept of teleology is a useful element of explaining adaption, when using the goal-directedness to explain the composition and processes of systems [47]. On the other hand, a teleological approach can put us on the wrong foot as explained in the review "If bone is the answer, then what is the question?" describing the increasing understanding of adaptive bone architecture over time [48]. Thus, the principles that facilitate adaption, especially the principles of biological evolution may serve as idea generators and may have great potential to contribute to sustainable solutions, precisely because the challenging situation that the stable preservation of certain ecological systems requires constant changes. However, this proposed transferability cannot be seen as an automatic transfer and has to be investigated thoroughly. Furthermore, what is called the social pillar of sustainability has no counterpart in biological systems and no direct conclusions concerning social aspects may be drawn from nature.

Although nature does not bear a fully comprehensible set of role models for a bio-derived understanding of sustainability, it undoubtedly is a great source of inspiration in terms of multiple aspects. The dynamic adaptation and the efficient utilization of locally and currently available resources but especially the fact that biological systems have been optimized in the course of evolution are fundamentals that qualify biological systems as role models for innovation. This mainly bears the potential for environmentally optimized solutions and offers economic potentials as well as these are related when it comes to efficiency. If one looks at the interaction between sustainability and biology from the perspective of the assessment of sustainable development, the question arises as to what commonalities this can be built on. Although the differences are also reflected in the different definitions of function and resource in biology and technology, the ratio between function and resource seems very promising.

\subsection{Bio-Inspired Sustainability Assessment}

One fundamental question when it comes to deriving solutions from biological systems is if living nature actually does provide a fully comprehensive counterpart to what is described as sustainability. The underlying proposition is that if nature is chosen as direct role model, its solutions should have been created considering the same framework conditions that are applied for sustainability assessments. If not, any direct transfer from nature cannot be stated as to create sustainable solutions by itself and the overall concept of sustainability has to be accepted as to be at least partially independent from our understanding of nature and thus artificial. To derive a robust answer to this question, both the concept of sustainability and the fundamental principles of biological systems have to be investigated. However, there are two main inconsistencies when trying to directly derive biological systems to sustainability metrics. First, the prevailing sustainability concept is explicitly anthropocentric and thus does not relate to the nature of biological systems. This becomes apparent by several intrinsic properties of sustainability paradigms such as the explicit focus on mankind in the UN but also when applied as assessment framework [21,26,49]. The second inconsistency arises from the concept of social sustainability that is still under discussion [50,51].

With regard to these considerations sustainability as bio-inspired concept is defined through the interdependence of system functions and the therefore required depletion of resources. A system is defined as sustainable, when a specific set of functions is fulfilled while simultaneously ensuring the ongoing availability of resources in time. The concept depicted in Figure 2 shows the predominant transformation direction of the prevailing economic metabolism, which is to create social functionality by depleting environmental resources driven by economic facilities. The graph is meant to show the dynamics of this metabolism indicating a sustainable system when its shape is kept stable, ensuring an ongoing provision of resources for an ongoing creation of function. Economy is interpreted as means 
to an end transforming resources into functions, enabling business models and thus facilitating the application of new products. Besides this main flow direction many processes are motivated otherwise and a general rule cannot be derived. The concept deals as a template to depict mechanisms of actions in terms of the fulfilment of functions including its intended and unintended effects. Nevertheless, it is quite uncommon for processes to dedicatedly create an environmental function or not utilize the environmental resources in a depleting manner. Furthermore, the predominant role of Economy is depicted as connecting element between Society and Environment. To keep this metabolism sustaining it is crucial not to exploit the resources to an extent that prohibits the ongoing fulfilment of societal functions. A sustainable system according to this scheme is achieved if the dynamic societal metabolism is maintained and is kept stable under dynamic conditions. It enhances the existing models through the integration of positive aspects and offers a shell like structure that is able to integrate different assessment methods.

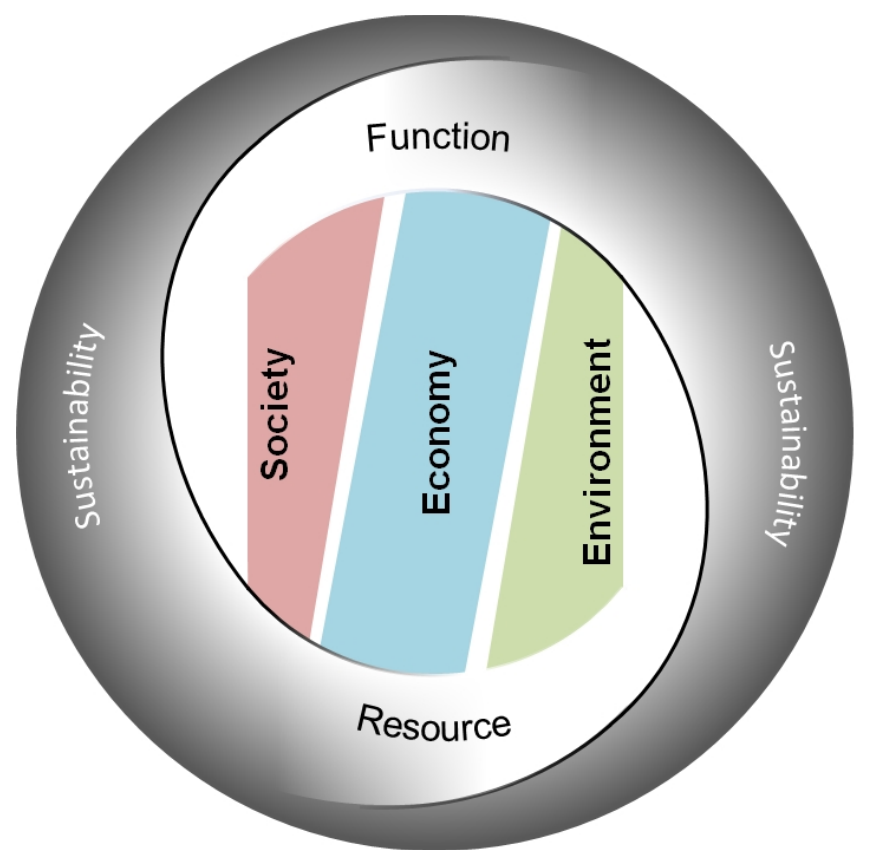

Figure 2. Bio-inspired Sustainability Assessment depicted as conceptual structure, showing the three dimensions called society, economy and environment and the two aspects, namely function and resource as integral parts of the assessment. Societal functions are fulfilled through the transformation of environmental, economic and societal resources (own figure).

In the following, a quantifiable BiSA model is presented based on a six-fold structure including the three dimensions of sustainability for both intended and unintended aspects called functions and burdens:

- Environmental burden: the unintended impacts of the assessed system to the environment based on an environmental life cycle assessment

- Environmental function: the dedicated design functions aiming at positively impacting the environment, calculated based on environmental life cycle assessment

- Economic burden: the life cycle related costs calculated based on the life cycle assessment model completed through process immanent costs and nonmaterial costs

- Economic function: the economic function from the point of view of the shareholders, calculated as economic profitability

- Social burden: the unintended effects of the assessed system on human society, calculated as impact on human capabilities and health, calculated based on environmental life cycle assessment 
- Social function: the primary design function restricted to the intended building physical function of the assessed system

The aspects are focused on the development of bio-inspired and bio-based products in the construction sector but are not restricted to these. The assessment aspects are chosen in terms of consistency and applicability with the main intension to provide feedback on decisions during product development. Its bio-inspiration lies primarily in its intrinsic setup inspired by biological systems and the overall structure of resource-function-relationships. The underlying physical model is created as a life cycle inventory system based on the GaBi database and supplemented by economic and country related information on process level. This model provides a consistent quantitative basis for 5 of 6 aspects. Moreover, it is applicable for both early and advanced development phases as it provides generic data but can include specific primary data as well. This facilitates a flexible structure and level of detail allowing the specification of the system as precisely as possible while still being able to estimate the coarsely defined aspects. The model has been implemented as semi-automatic tool to provide feedback for specific questions within the embedding project but has not been created as software for automatic application yet. However, an increased level of automation is envisaged for the next project phase.

\subsubsection{Environmental Burden}

The depletion of natural resources is the main source of human prosperity and as such of central relevance for the assessment of bio-inspired sustainability. Building upon the treatment of resources in biological systems, similarities can be identified mainly in terms of the dependency from physical sources. As mentioned before, all ecosystems are dependent on biotic (living) and abiotic (nonliving) environmental factors. In the course of the earth's history it has been shown, that especially after mass extinction source-sink dynamics influence the variation in habitat quality affecting biodiversity, population growth and number of organisms [52]. Even though it is repeatedly claimed that nature does not produce any waste, this is not the case on closer inspection. For example, most of the crude oil produced today originates from dead marine organisms, buried underneath sedimentary rocks. The deposits are therefore nothing more than landfills for fossilized organic materials or in other words natural waste. Thus, the use of fossil fuels such as coal, natural gas and crude oil hydrate is associated with respective $\mathrm{CO}_{2}$ emissions.

The environmental burden is calculated by LCA, using a single point value based on a selection of characterization methods. The steps that are to be performed when conducting an LCA according to the pertinent standards cannot be fully applied due to the interactive nature of the BiSA assessment [53-55]. Nevertheless, the functional unit, the system boundaries and consistent specifications of the applied calculation principles such as allocation and cut-off criteria have to be stated. Furthermore, the life cycle inventory models for each of the assessed systems and variants have to be created. This model was created using the Software GaBi 8.2 (thinkstep, Leinfelden-Echterdingen, Germany), which is one of the world's leading LCA software providers and the GaBi SP 34 (thinkstep, Leinfelden-Echterdingen, Germany) database, providing more than 10,000 environmental profiles as a modeling basis [56]. For the assessment of the environmental burden it is possible to directly derive indicators and weighting schemes from the investigation of natural systems. This is, on a quite abstract level, the transfer of biophysical system stability as role model on global scale. A quantifiable concept to address the issue of global biophysical system stability was introduced by Rockström et al. in 2009 and has been since then further refined and continuously updated [5,57]. It identifies the main biophysical systems that are threatened by human activities and provides a framework to quantify planetary boundaries that should not be exceeded by mankind on global scale if the global ecosphere is to be kept intact. The concept provides an approach to address the manifold depletion of nature by man and is subject to the ongoing development to include new insights of scientific discourse. The planetary boundaries have been transferred to deal as life cycle assessment weighting scheme by several authors [58-62]. The approach proposed by Sala et al. is chosen and adapted using the presented values for distance-to-target 
normalization due to the fact that a single value for the environmental burden is required [59,63]. In addition to this approach, the areas of protection are differentiated in sink and source related categories. Sink related categories are summarized as global biophysical system stability and correlate directly to the biological system they depict. As the ongoing availability of both biotic and abiotic resources is crucial for the metabolism stated above, the depletion of resources is classified in the area of global resource stock. Strictly seen the availability of resources for mankind is mainly underground and does not directly contribute to the stability of the biophysical system but is crucial for the concept of scarce resource utilization prevailing in biological systems. Due to significant methodological improvements since the publication of the distance to target values, the abiotic depletion potential is covered by the anthropogenic stock extended abiotic depletion potential (AADP) model and for land use the biotic production indicator as published in LANCA 2.0 (Fraunhofer IBP, Stuttgart, Germany) is applied, which is freely available in the updated version [64-67]. Nevertheless, the assessment of impacts on the global resource stock still bears strong potentials for improvement, especially in terms of temporal and spatial differentiation. Table 1 shows the considered categories and the according normalization factors as well as the chosen methods to quantify the impacts of each category. The results of each impact category over the whole life cycle are multiplied with the normalization factor based on the planetary boundary concept. The normalized values are then added, creating a single point that can be directly compared to the one of the reference system, which is created similarly.

Table 1. Categories and weighting structure for the assessment of the environmental burden derived from [59].

\begin{tabular}{|c|c|c|c|c|}
\hline Area of Protection & Impact Category & Abbreviation & $\begin{array}{c}\text { Impact Assessment } \\
\text { Model }\end{array}$ & Normalization \\
\hline \multirow{8}{*}{$\begin{array}{l}\text { Global biophysical } \\
\text { system stability }\end{array}$} & \multirow{2}{*}{$\begin{array}{l}\text { Climate change } \\
\text { Ozone depletion } \\
\text { potential }\end{array}$} & GWP & IPCC & $4.81 \times 10^{13}$ \\
\hline & & ODP & CML & $1.34 \times 10^{8}$ \\
\hline & $\begin{array}{l}\text { Photochemical } \\
\text { ozone formation }\end{array}$ & POF & ReCiPe & $2.80 \times 10^{11}$ \\
\hline & $\begin{array}{l}\text { Freshwater } \\
\text { eutrophication }\end{array}$ & EUTF & ReCiPe & $1.76 \times 10^{10}$ \\
\hline & $\begin{array}{c}\text { Marine } \\
\text { eutrophication }\end{array}$ & EUTM & ReCiPe & $1.95 \times 10^{11}$ \\
\hline & $\begin{array}{l}\text { Freshwater } \\
\text { ecotoxicity }\end{array}$ & FRTOX & UseTox & $4.46 \times 10^{12}$ \\
\hline & Acidification & $\mathrm{AC}$ & TRACI & $3.83 \times 10^{11}$ \\
\hline & $\begin{array}{c}\text { Terrestrial } \\
\text { eutrophication }\end{array}$ & EUTT & TRACI & $1.22 \times 10^{12}$ \\
\hline \multirow{4}{*}{ Global resource stock } & Land use & LU & LANCA & $1.00 \times 10^{15}$ \\
\hline & Water depletion & WD & WSI & $4.81 \times 10^{13}$ \\
\hline & Resource depletion & \multirow[t]{2}{*}{ AADP } & AADP & $3.70 \times 10^{9}$ \\
\hline & $\begin{array}{c}\text { Biodiversity } \\
\text { depletion }\end{array}$ & & - & - \\
\hline
\end{tabular}

\subsubsection{Environmental Function}

As defined in the framework, functions are considered to be intended properties of the assessed system. For environmental functions this requires an explicitly specified positive impact on the environment. A very well-known biological example is mutualism, a relationship between different species with positive impact insofar as that both individuals benefit. The biological barter can be a resource-resource-relationship (e.g., mycorrhizal associations between plant roots and fungi) or a service-resource relationship (e.g., birds disperse plant seeds of fleshy fruits that they have eaten before) or a service-service-relationship (e.g., sea anemones and anemone fishes protect each other from their respective predators). In addition to these mutual relationships, a large number of closed material cycles (e.g., carbon cycle, nitrogen cycle, sulphur cycle and phosphorus cycle) are known, in which the starting material is finally available again through periodic transformation of chemical compounds. 
Most technical systems do not have a specific environmental function and are consequently not assessed for this aspect. However, for systems which specifically intend to improve the accessibility of their wastes, such as waste treatment systems, or for systems that intend to transform their wastes to be suitable for others in a mutual form, the environmental function can be assessed and quantified. As the same system is investigated, the same assessment structure as for environmental burden is applied and defined as positive intended impacts. Life cycle related indirect effects such as recyclability in general are considered for burden assessment, as they are not regarded as intended design function [42].

\subsubsection{Economic Burden}

In contrast to environmental burdens, the economic ones are directly related to the success of a product meeting a demand (or providing a function) under ideal market conditions. In real markets, this is interleaved with numerous adaptations such as subsidies, taxes, cross funding, market distortions and many more. However, the economic burdens and its underlying structure are a key aspect of any artificial system. They depict the resource demand of the product scaled by the scarcity of its constituting elements in the actual economic conditions. Scarcity is created as an artificial value based on availability and demand. It is modified by the adaptations stated above and is represented by the price of each element, which deals as intermediary and as such facilitates flexible handling of resources. Even though most nonhuman biological systems do not have an intermediating currency its resource demand is also strongly affected by the scarcity of the constituting elements such as water, solar energy, space or trace minerals.

The economically expressed scarcity in terms of a monetary cost structure determines the aspect of economic burden. It depicts the restrictions and framework conditions that are imposed through the embeddedness of the product in the economic system. While the relevance of each constituting element is different to the environmental burden contribution, the system that is taken into regard is ought to be consistent. The method of Life Cycle Costing (LCC) provides such a consistent framework and can be regarded as consolidated in sustainability science [68]. However, it does imply several fundamental differences due to time relatedness and the consideration of nonmaterial elements and is therefore applied in a multistage adaptation, starting with process immanent costs (PIC) and including further nonmaterial information (FNI) if available. Table 2 depicts the categories that are differentiated in the economic burden assessment. As they all are assessed in monetary values, they can be added without weighting. The assessment of the different cost categories is an integral part of the enhanced Life Cycle Inventory (LCI) model, that has been created through coupling the GaBi database with statistical cost data through the mapping of flows to sectors based on European statistics [56,69]. Thus, the cost structure can automatically be derived for the complete LCI model, providing the same system boundaries and level of detail than for the environmental assessment.

Table 2. Categories and weighting structure for the assessment of the economic burden.

\begin{tabular}{ccc}
\hline Area of Protection & Impact Category & Impact Assessment Model \\
\hline \multirow{4}{*}{ Variable Costs } & Resource costs & PIC \\
& Electricity costs & PIC \\
& Other energy costs & PIC \\
& Labor costs & PIC \\
& Machine costs & FNI \\
Fixed costs & Disposal costs & FNI \\
\hline \multirow{2}{*}{ Process related investments } & FNI \\
& Infrastructure costs & FNI \\
\hline
\end{tabular}

In contrast to most Life Cycle Costing models, the model does not include time-related price change or discount rates, as this is not yet possible in the enhanced LCI model. This however ensures consistency with the environmental burden aspect, as there are no discounting issues considered as 
well. However, this simplification comes along with several drawbacks in comparability to other economic analyses including potential communication issues.

\subsubsection{Economic Function}

Economic viability is a crucial prerequisite for any technical system and is usually defined as feasibility in terms of a business model or economic product life cycle. While it is oftentimes not the ultimate purpose, economic viability is an essential means to function fulfilment, which is why the economic function is regarded as separate aspect.

Even though no direct analogy can be drawn between nonhuman biological systems and economic viability, its basic function offers some similarities between evolutionary fitness and economic success [7]. The behavior of companies is to some extent comparable to evolutionary mechanisms of selection and niche occupation, as indicated through analogies in terminology [70]. The two main areas of protection are derived from this analogy and are defined as profitability (efficiency) and competitiveness (fitness). While these aspects are addressed in detail in business practices, they are oftentimes not regarded within product development, especially in early development phases. Therefore, a basic system shown in Table 3 is proposed based on the framework presented above, combining PIC and FNI. On the basic level, the material and energy cost optimum is related to a potential market price based on existing competing products. These values are then complemented through further nonmaterial information on labor costs, investment goods and detailed information on the market situation including potential market prices as well as a potential product price and market volume estimation.

Table 3. Categories and weighting structure for the assessment of the economic function.

\begin{tabular}{ccc}
\hline Area of Protection & Impact Category & Impact Assessment Model \\
\hline \multirow{3}{*}{ Profitability } & Production costs & PIC \\
& Current market price & FNI \\
& Cost reduction potential & PIC + FNI \\
\hline \multirow{2}{*}{ Competitiveness } & Current market price & FNI \\
& Potential market price & FNI \\
\hline
\end{tabular}

\subsubsection{Social Burden}

In contrast to economic and environmental aspects, the definition of social burdens cannot be derived from a state of the art assessment methodology. The main difference can be identified in the ambiguity of social impacts in terms of goal and scope and the fact that the physical quantification for most categories is not applicable due to its immaterial nature [71]. While for social life cycle assessment no method has prevailed yet, a guideline providing general recommendations was published by the United Nations Environment Programme [50,51,72]. Furthermore, Sureau et al. have investigated 14 different frameworks for social LCA and identified high diversity between the approaches as well as substantial demand for further development [49]. From an epistemological point of view, the underlying scientific paradigm is differing between post-positivism- and interpretivism-oriented approaches [73]. While interpretivism-based approaches are aggregating impacts that are mainly chosen case specific with regard to stakeholder groups, interpretivism-oriented approaches are developed in analogy to environmental LCA, trying to provide quantifiable, generally valid impact pathways to be applied to life cycle system models [74]. While the thereby developed methods differ in their approaches to choose and define indicators and assess its inherent impacts, their common denominator is the identification of effects of a system's life cycle with regard to social aspects based on explicitly or implicitly chosen frameworks.

Looking at nonhuman biological systems, ethics, morality and altruism are concepts that do not seem to be relevant in most biological (non-human) systems, even though exceptions are known $[75,76]$. 
Though still subject to scientific controversy, morality and altruism and the consequent concept of ethics may be an integral part of the evolutionary success of humanity and are therefore key to its understanding and its ongoing success $[77,78]$. The assessment of social burdens is therefore interpreted as the depletion of societal resources, which are defined as human health and human capabilities. These are the basic prerequisites for humans to live a self-determined life and for society to prosper [79]. Human health is assessed through the LCA model, applying the same distance to target normalization approach as for environmental burdens for the human health related impact categories (Table 4) [59]. Again, the proposed impact categories are replaced by updated version if available, which in the case of human health applies to the USETOX model [80]. The concept of human capabilities to address social impacts has been developed based on the capability approach as framed by Sen $[79,81]$. It is applied in a hybrid approach using the Social Hotspots Database (SHDB) for quantification of the impact categories based on risk levels, which are available on country and sector level [82]. The risks are linked with the product system using a bottom-up approach to assign working time to each unit process of the model based on statistical data according to an updated and extended version of the Life Cycle Working Environment (LCWE) method. The chosen method can be characterized as environmental LCI database method according to the differentiation provided by Chhipi-Shrestha et al. (2014) [73]. The model is integrated in the GaBi software and thus applicable using the enhanced LCI model, providing working time in seconds for both aggregated and unit processes. While the method is still under development, it has already successfully been applied in several research projects [83-85]. The indicators are each calculated as both total working seconds under high and very high risk of each category and its share related to the overall working time. The indicators have been chosen based on the framework introduced by Reitinger et al., 2011, which adds fairness to the categories introduced by Sen $[79,86]$. To prevent double counting, the aspect of health and safety is covered by the LCA impact assessment and not included in the capability assessment.

Table 4. Categories and weighting structure for the assessment of the social burden.

\begin{tabular}{|c|c|c|c|}
\hline $\begin{array}{c}\text { Area of } \\
\text { Protection }\end{array}$ & Impact Category & $\begin{array}{l}\text { Impact Assessment } \\
\text { Model }\end{array}$ & Considered Categories/Normalization Values \\
\hline \multirow{6}{*}{$\begin{array}{l}\text { Human } \\
\text { capabilities }\end{array}$} & Political freedoms & SHDB & $\begin{array}{l}\text { Freedom of Association, Collective Bargaining, } \\
\text { and Right to Strike }\end{array}$ \\
\hline & Economic facilities & SHDB & Wage Assessment; Poverty; Labor Laws \\
\hline & Social opportunities & SHDB & $\begin{array}{c}\text { Children Out of School; Child Labor; Working } \\
\text { Time; Forced Labor }\end{array}$ \\
\hline & Transparency guarantees & SHDB & High Conflict Zones; Legal System; Corruption \\
\hline & Protective Security & SHDB & $\begin{array}{l}\text { Access to Improved Sanitation; Access to Hospital } \\
\text { Beds; Access to Improved Drinking Water }\end{array}$ \\
\hline & Fairness & SHDB & $\begin{array}{c}\text { Gender Equity; Migrant Workers; Indigenous } \\
\text { Rights }\end{array}$ \\
\hline \multirow{4}{*}{ Human health } & $\begin{array}{l}\text { Human toxicity, cancer } \\
\text { effects }\end{array}$ & USETOX (V 2.01) & $9.16 \times 10^{4}$ \\
\hline & $\begin{array}{l}\text { Human toxicity, } \\
\text { non-cancer effects }\end{array}$ & USETOX (V 2.01) & $1.13 \times 10^{6}$ \\
\hline & $\begin{array}{c}\text { Particulate } \\
\text { matter/Respiratory } \\
\text { inorganics }\end{array}$ & USETOX (V 2.01) & $6.86 \times 10^{10}$ \\
\hline & Ionizing radiation & $\begin{array}{c}\text { Human Health effect } \\
\text { model (V1.09) }\end{array}$ & $2.04 \times 10^{12}$ \\
\hline
\end{tabular}

\subsubsection{Social Function}

The function of a technical system can ultimately be defined as to serve a specific, desired purpose. While these functions can be distinguished between design functions, use functions and service functions only design function can be considered for product development as this is the function that 
was designed as a means of achieving its end [42]. It is therefore a crucial aspect to be considered when designing or developing products to address the specific function or functions.

In biological systems, the concept of function is defined differently and mainly applied with regard to evolution and fitness $[41,87]$. Nevertheless, it is possible to investigate and quantify physical properties of biological systems with regard to their technical design function. Especially in biomimetic science, the identification of these functional principles is key to successfully transfer its core working principles to technical solutions [88]. To define these technical design functions with focus on the area of application of this model, the building physical functions specified by Moro are applied as design functions (see Table 5) [89]. As most products are only focusing on one or a few of these functions, the use of a generalizable quantification system for all categories was not applied. The presented impact categories and the according building physical functions shall be used as catalog to choose the design function including multifunctional properties, each of which then should be assessed individually based on the according building physical properties. When a product is developed as load bearing element, for instance, its design has to be chosen to bear not less load than the reference system and its dimensioning has to be chosen accordingly.

Table 5. Categories and weighting structure for the assessment of the social function, restricted to building physical functions [89].

\begin{tabular}{cc}
\hline Area of Function & Impact Category \\
\hline \multirow{2}{*}{ Load bearing } & Primary support structure \\
& Secondary support structure \\
& Tertiary support structure \\
\hline & Vapor balance control \\
Indoor acoustics conditioning \\
Protection against infiltration \\
Privacy, glare and sun protection \\
Fire protection \\
Noise protection \\
Illumination \\
Natural ventilation \\
Thermal conditioning \\
Electricity control and supply \\
Supply and disposal & Water supply \\
& Lighting \\
& Cooling supply \\
& Heating supply \\
\hline
\end{tabular}

\section{Application}

The proof of general compliance to the requirements that have been identified as relevant to qualify the BiSA requires ongoing application. As the assessment system is developed as part of an ongoing project, its ongoing application is ensured through the ongoing project integration. However, to depict the basic functionality of the assessment the biobased and biodegradable composite Bio-flexi will be presented in the following. This specific exemplary application is chosen and presented including technology introduction, technical description, assessment results and discussion.

\subsection{Bio-Flexi-A Biobased and Biodegradable Composite}

The Bio-flexi innovation is a biocomposite fiberboard manufactured from annually generated agricultural residues' fibers in the form of a flexible high-density fiberboard. The raw agro-fibers were bonded till $90 \%$ of mass load, without pre-chemical modification, by a thermoplastic elastic binder (TPE) using classic plastic-industry machinery [90]. The fibers applied were chosen from the agricultural residues stream, namely straw, which is the cheapest non-wood lignocellulosic natural 
fiber abundantly available worldwide from the cereal crops by-products' streams, mainly out of wheat, rice and maize. As the fibers are not edible, the discussion on competition with food is not relevant here. Other than availability, these lignocellulosic fiber types were applied to actively replace mineral-based flame retardants in plastics, depending on the high natural silica contents naturally present in their chemical composition reaching up to $20 \%$ of mass load in certain types as in the case with rice straw. The selected TPE binder was purposely chosen to be biodegradable under industrial compost conditions to give an opportunity to have multiple end-of life options after the end of the useful life time of the developed biocomposite material. These combined parameters were applied to increase the positive environmental feedback of this development during and after the useful life time of application in the building industry. It has at least two end-of-life options as it can be recycled to a number of recycling cycles then industrially composted if further recycling cycles would not be feasible, which is a solution that helps in minimizing wastes' accumulation. Waste accumulation minimization is accordingly hereby achieved twice: once during the production phase, as it is mainly based on agricultural residues fibers and secondly after the end of its useful life time. These end-of-life options are rarely available in the contemporary fiberboards market worldwide, the thing that promotes a wider application of this development in the contemporary building industry replacing a wide range of non-recyclable petro-based building products.

Usage of agro-fibers with these high mass-loads (up to $90 \%$ mass load) will help replacing the slow-renewable wood and improve forestry practices. In addition to these ecologic values, the elastic nature of the developed fiberboard enables the possibility of achieving attractive free-form architectural interior designs using cheap alternatives and available production techniques. Flat horizontal applications like flooring systems as in sport halls, yoga mats and others as well as in vertical applications as partitions and interior fittings are possible. Usage of thin veneer covering layers is necessary in different applications to give a covering aesthetic feature, to offer a final reinforcing layer and to close open fiber pores to guarantee durability. The high density developed boards can be provided with minimal thicknesses starting from 1-2 $\mathrm{mm}$ and can be transported in the form of rolls to minimize transportation and storage costs. In Figure 3, flexibility and possible applications in both flat- and curved-morphologies are emphasized.
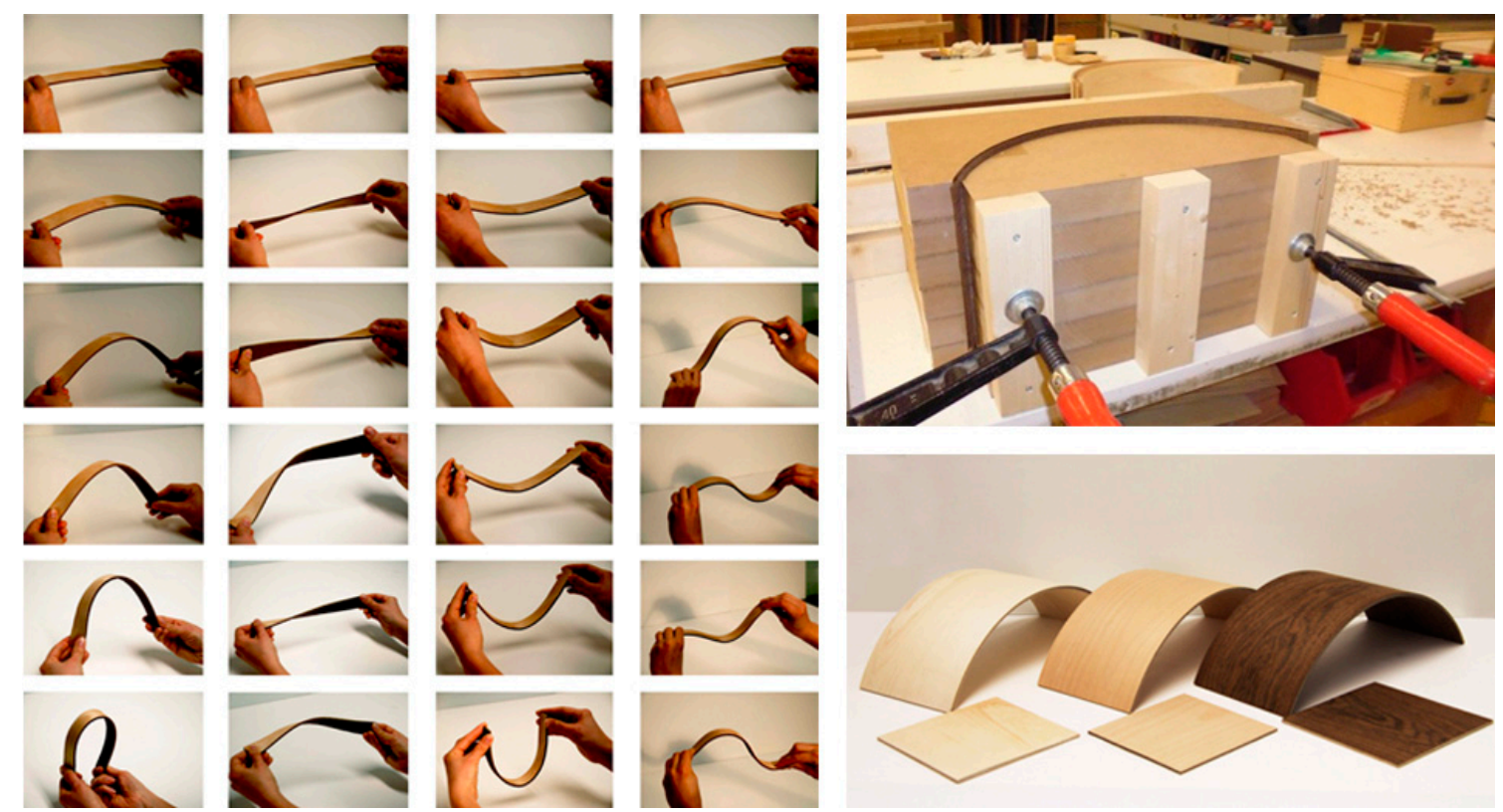

Figure 3. Illustration of the flexibility of the Bio-flexi panel when veneered from one side and how it can be veneered from both sides to fix the geometry intentionally (republished: [91]). 


\subsection{Technical Characterization}

The Bio-flexi panel was extruded using a double-screw extrusion machine, in which four heating canals existed to control heating temperatures throughout the longitudinal mixing path of the compounded mixture. At the heating canals as well as the feeding canal, gas absorbers were integrated to absorb water vapor arising from the natural fibers, which previously captured natural atmospheric humidity to optimize the mixture and eliminate any inhomogeneity or plasticity (Figure 4).

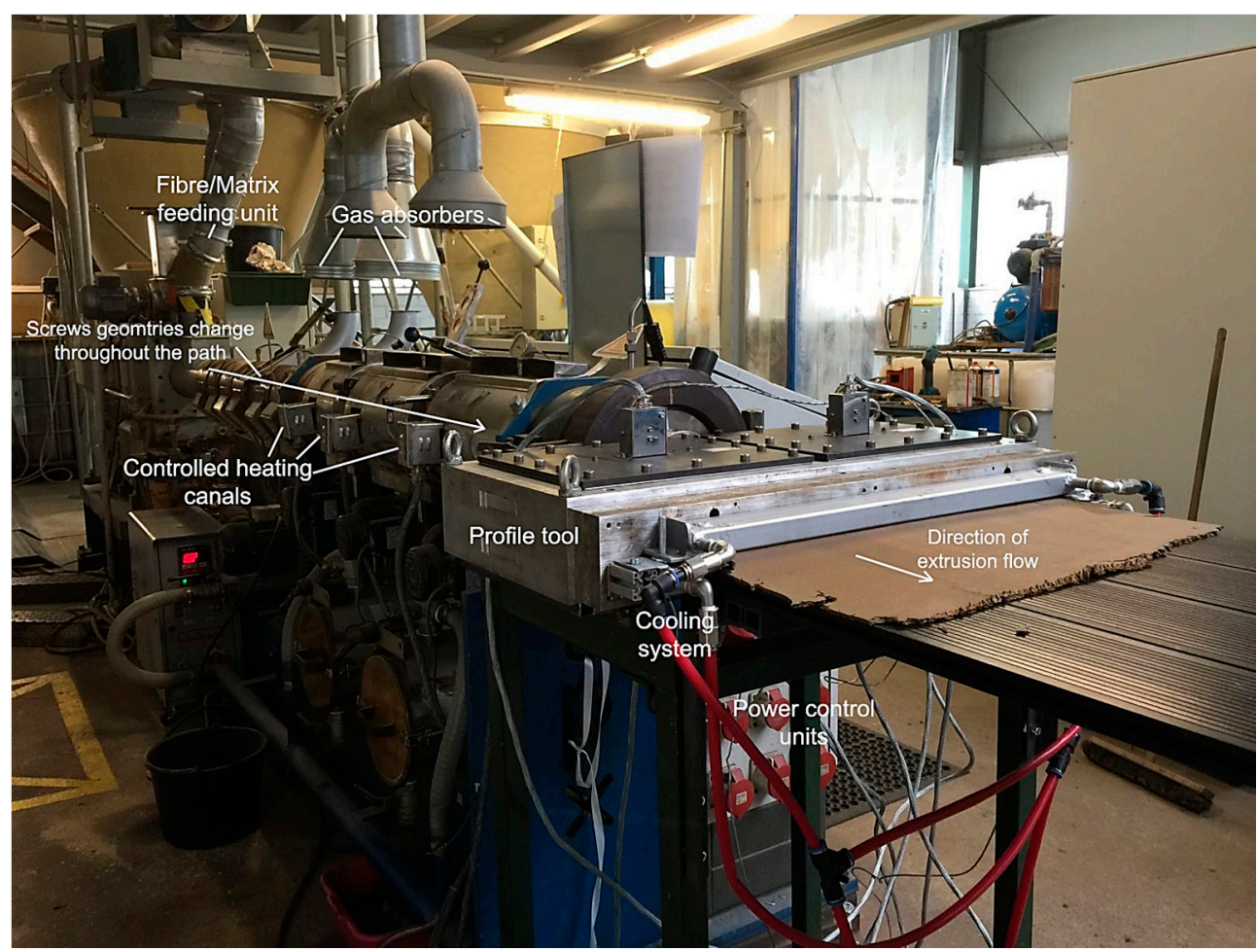

Figure 4. Illustration of the production of Bio-flexi in mass-production scale indicating the control and feeding units in Naftex GmbH company, Wiesmoor, Germany (Photo: Dahy, H.).

The developed Bio-flexi HDF product was mechanically tested to evaluate the transportation safety without distortion and the usage possibility in flooring systems in respect to residual indentation after DIN EN 433 and indentation resistance after DIN EN 1516, to evaluate if the product can be applied in the scope of flat flooring in sport halls [92]. To validate the possibility of applying this material in flooring systems, the fiberboard was tested under static loads to measure thickness losses, as a step to measure its residual indentation and indentation resistance. Measurement of residual indentation after DIN EN 433 simulates the static furniture loads. The result indicated that Bio-flexi at $80 \%$ fiber-load by mass has a residual indentation of $0.14 \mathrm{~mm}$, which is comparable with other elastic flooring materials as Linoleum that lies between $0.07-0.4 \mathrm{~mm}$. To validate the resistance to indentation of elastic surfaces for sport areas, DIN EN 1516 test standards were applied to determine that the permanent change in the flooring plate thickness was only $0.02 \mathrm{~mm}$ that fits in the range set in this standard not exceeding $0.5 \mathrm{~mm}$ permanent thickness loss. This indicates that the developed fiberboard can be applied in flooring systems in sport halls, sport activity areas and in cushioning services [91].

Under the raising awareness of the environmental possible drawbacks of all newly developed building materials, thermoset matrix application was eliminated here and a thermoplastic elastomeric binder (TPE) was applied instead. Recyclability is here guaranteed without further experimental proof dependent on the thermoplasticity of the binder and the high heat-resistance of the natural fibers reaching to $220^{\circ} \mathrm{C}$ depending on the flame-resistant silica loaded contents, which should enable multiple recycling cycles before the fiber deteriorates. However, in the area of Natural Fiber Reinforced 
Polymer Composites (NFRP) recycling virgin thermoplastic binders of the same or another compatible base as well as virgin natural fibers are needed to be added in small ratios in each recycling cycle to guarantee preserving the same original quality of the first produced series. The composting option was otherwise experimentally proved through soil burial tests that were conducted for 15 months, where the samples were buried in a chosen field plot in the middle of the Stuttgart city in South Germany. Compostability conditions were set so that aerobic bacteria at a level of maximum $-8 \mathrm{~cm}$ under the soil's surface were activated, to measure if or not the test samples will start decaying. Weight reduction was monitored and visual qualitative inspection took place each 3 months. By the end of the test, plant roots were observed growing within the samples' bodies and a final weight reduction of around $41 \%$ after 15 months of soil burial were measured. Through these results, it was concluded that the Bio-flexi fiberboard has also the tendency to be industrially composted as a second end-of life option in addition to its recyclability. In Figure 5, the closed cycle graph of the Bio-flexi according to the cradle to cradle ${ }^{\circledR}$ design conception is shown including the two main product circles that are impacted by the Bio-flexi life cycle.

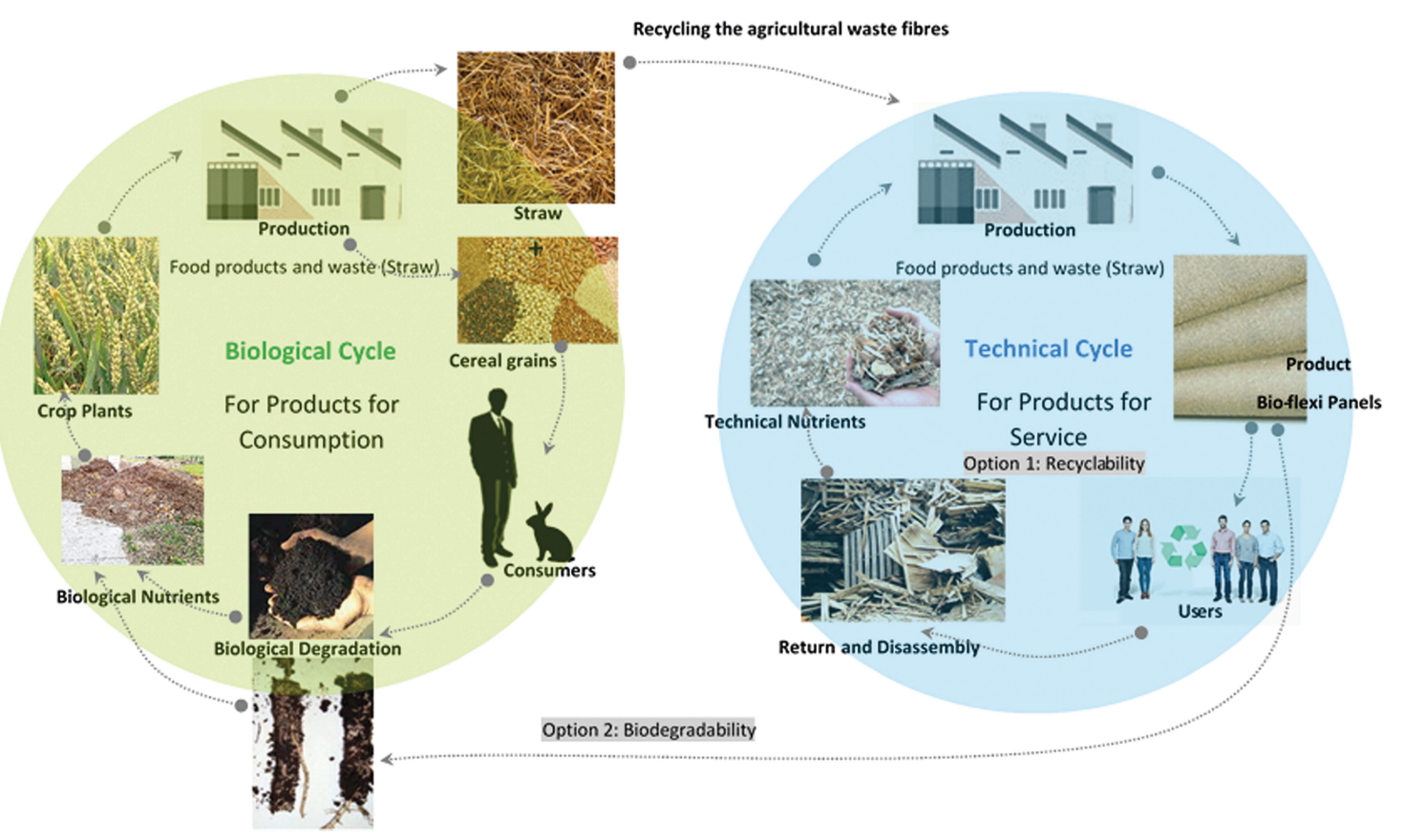

Figure 5. Graph indicating the closed proposed cycle of the Bio-flexi HDF fiberboard after the cradle to cradle ${ }^{\circledR}$ concept (Photo: Dahy, H.).

\subsection{Bio-Inspired Sustainability of Bio-Flexi}

The assessment of Bio-flexi is performed based on a system model that has been created in analogy to the Life Cycle Inventory model in LCA. For the modelling, the LCA software GaBi was used [56]. In analogy to LCA, the goal and scope definitions are presented in the following. Goal of the assessment is to investigate the sustainability of Bio-flexi in a sports facility flooring application compared to a conventional reference system, for which a polyurethane based flooring material is chosen. One square meter of flooring material is chosen as functional unit. As the complementing build up is assumed to be similar for both systems, the comparison is restricted to these surface layer materials, also providing the basic functions of shock absorption and cushioning in a comparable way. The service life is defined as 20 years and no difference in maintenance is considered.

The technical characterization has been transferred to a Life Cycle Inventory model using primary data provided by the manufacturers including the life cycle phases A1-A3, C3 and D [93]. As the technology provides two EoL-options, a sensitivity analysis has been conducted, resulting in two 
different scenarios that depict the most realistic options. Scenario one is using a maximum amount of recycling and scenario two is treated through composting. In addition to the information given in the technical characterization, several additional processes were added to complement the life cycle with regard to recycling and composting. For the recycling option a grinding process has been applied to facilitate the recirculation of recyclate to the virgin raw material stream before the extrusion process takes place. A percentage of $20 \%$ was specified as maximum recyclate rate. For the composting option, an industrial composting plant model was chosen to estimate the according material decomposition rate in real application. As coarse material is removed showing a relatively low decomposition rate due to its small surface area, a grinding process is assumed here as well. For the remaining materials thermal utilization is assumed, using a dynamic energy mix based on German lead scenarios to calculate the benefits beyond system boundary [56]. The system boundary of the two scenarios is shown in Figure 6.

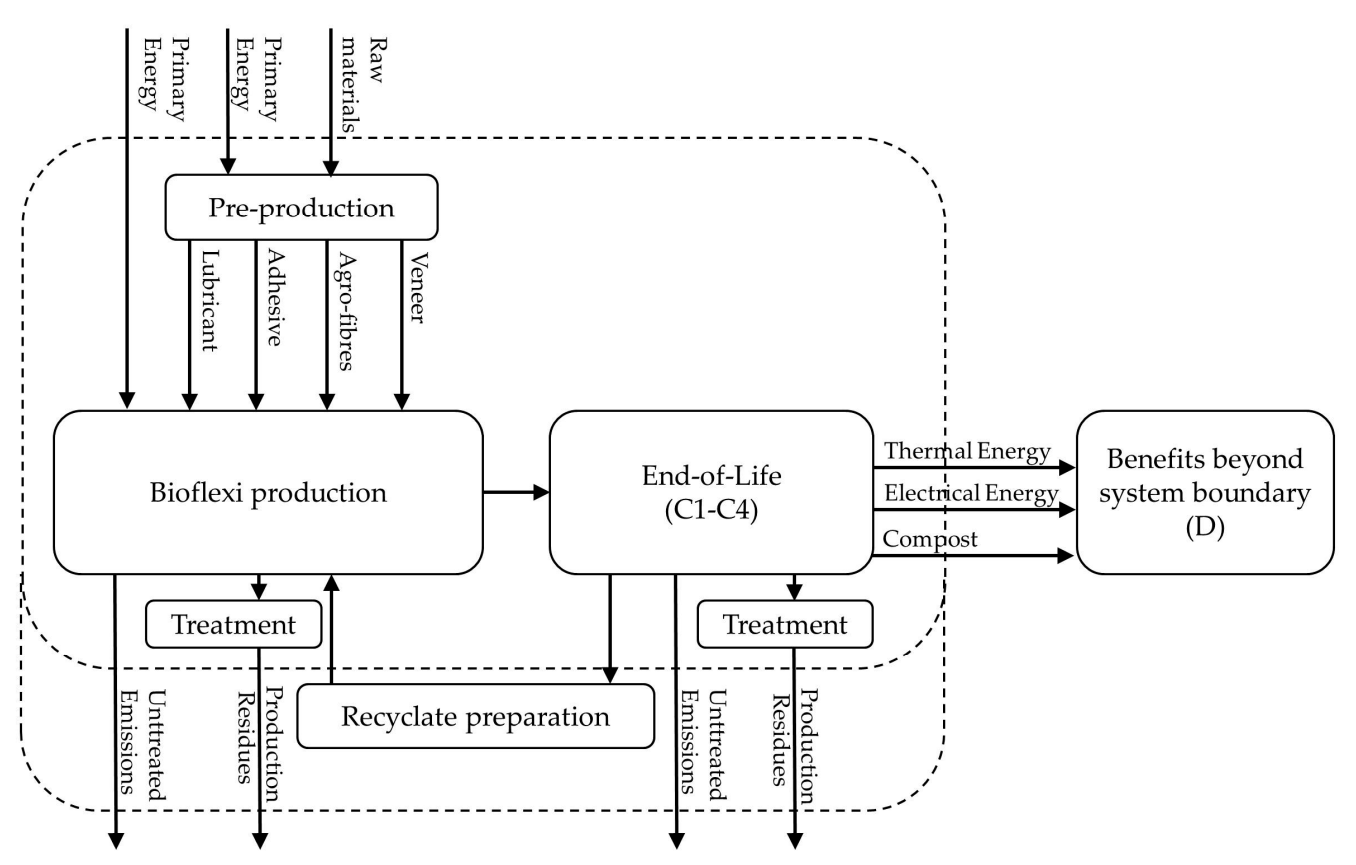

Figure 6. System boundary of the investigated life cycle inventory model. The main material and energy flows for production, End-of-Life and Benefits are shown. The recyclate preparation is only considered for the recycled scenario and therefore depicted separately.

The model was used as basis to perform a BiSA according to the assessment structure described above. As there is no decidedly specified environmental function, the environmental function is not investigated. For the economic assessment, a simplified approach is chosen due to the fact that Bio-flexi is still a product under development and a number of non-material information is not yet available. The social function in terms of building physical design functions is assumed to be comparable to the conventional reference product as indicated by divers tests [91]. In the following, the aspect environmental burden is presented in detail due to its relevance related to the motivation of the developers. Figure 7 depicts the overall environmental burden in normalized numbers, showing the overall environmental impact with regard to the planetary boundaries.

While the impact of the most relevant category for PUR is strongly reduced in both Bio-flexi scenarios, the overall impacts of all categories are almost compensating these savings for the recycled scenario and even overcompensating the savings for the composted scenario, having an increased in normalized impact by $17 \%$. The increased impact mainly origins in the agricultural system, which especially impacts on eutrophication and acidification. Overall, the recycling option already is 
comparable to the reference system and offers further saving potential especially when the recycling rate can be further improved.

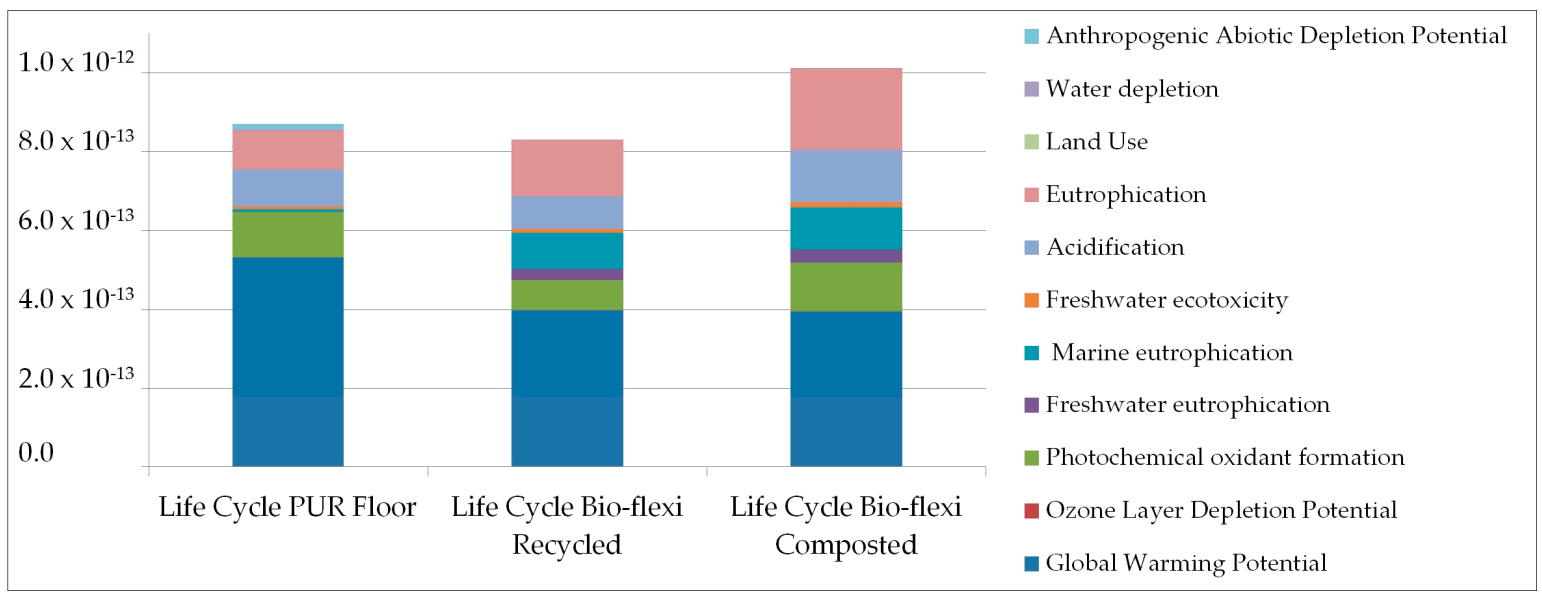

Figure 7. Environmental burden of the reference system and the two scenarios of Bio-flexi (Recycled and composted) as normalized results for the considered life cycle phases.

The overall sustainability assessment result is depicted in Figure 8. The segments are scaled in relation to the reference system using the radius as scaling element. Diagram (1) shows the recycled scenario, diagram (2) on the right hand side depicts the composted scenario. While for both economic and environmental burden only small changes can be identified, the social burden offers significant savings for both scenarios.
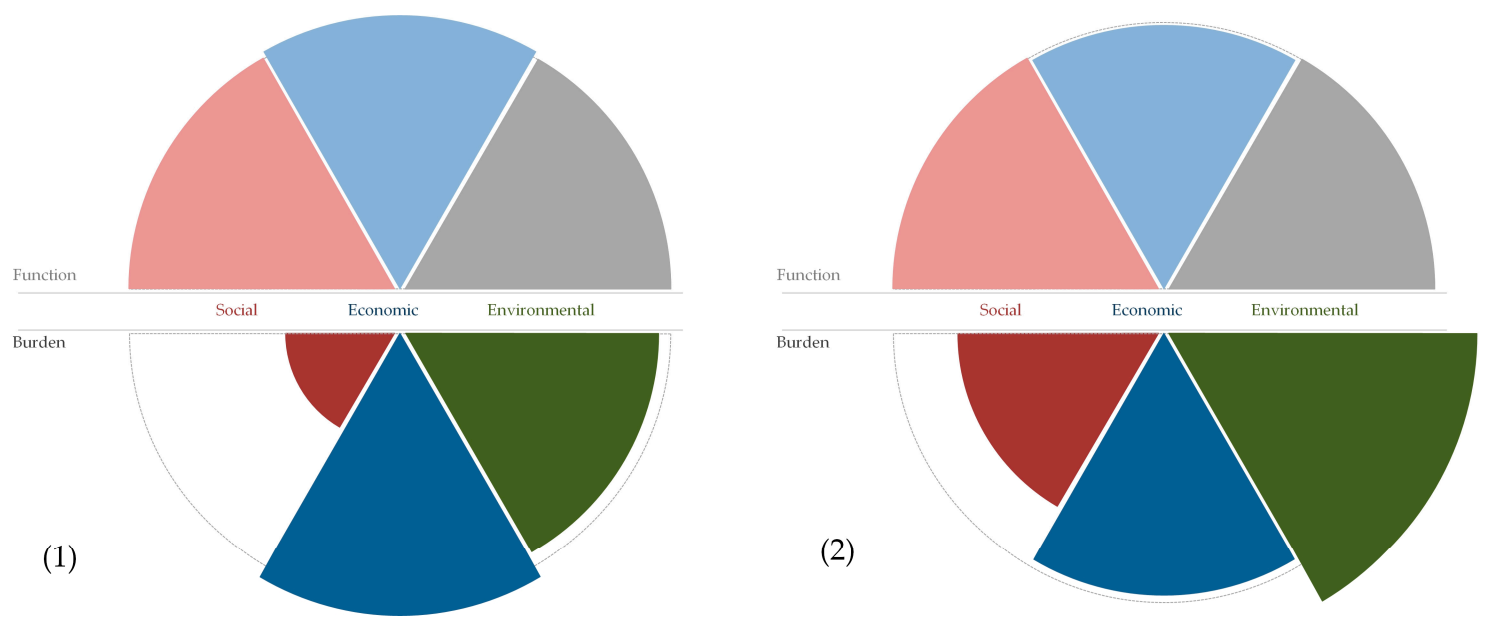

Figure 8. Bio-inspired sustainability of Bio-flexi as pie charts, including the six aspects of sustainability, each depicted by a specific color. The red elements depict the social aspects, the blue elements depict the economic aspects and the green element depicts the environmental aspects. As there is no environmental function of both reference and assessed system, the environmental function element is greyed out. Each aspect is shown in relation to the reference product, depicted by a grey circle line which is identical for both graphs. The relative value is depicted as change in pie element radius and therefore linear. (1) The recycled scenario shows Bio-flexi with a maximum of recycling compared to a conventional reference product. (2) The composted scenario shows Bio-flexi with a maximum of composting compared to a conventional reference product.

For both economic burden and function, the assessment was restricted to the process immanent cost model, where both scenarios provide a similar cost structure. The overall production costs 
are furthermore comparable to the conventional flooring material. For social burdens, a significant reduction of the impact on human capability has been identified. This mainly origins in the fact that the Bio-flexi production including its upstream material chain takes place mainly in Germany, while the fossil based reference product includes significant share of work with higher risk of human capability reduction mainly in the raw material extracting countries. The impact on human health does not provide significant saving potentials for the composted scenario and is increased by $51 \%$ due to the impacts occurring in the composting process. For the recycled scenario, a reduction of $25 \%$ of normalized impact in comparison to the reference system is determined. Overall, the recycled scenario offers a higher potential with regard to bio-inspired sustainability, although this does not apply to each aspect concurrently. The main improvement could be identified in the reduction of social burdens and global warming potential, while no significant change could be identified for economic aspects for both function and burden.

The biobased and biodegradable composite Bio-flexi appears to be able to compete in terms of bio-inspired sustainability with its conventional, fossil-based reference in the application as flooring system in sports facilities. In contrast to the reference, however, Bio-flexi bears several additional optimization potentials and is expected to be generally beneficial when further developed under consideration of the decision support provided by the BiSA system. Especially with regard to recyclability, improvement potentials have been identified, as the recycled Bio-flexi scenario provides significant improvements in environmental and social burden compared to both the reference system and the composted Bio-flexi scenario. While product development continues, economic function and burden assessment can be specified further, focusing on nonmaterial information. Nevertheless, the already competitive process immanent costs indicate potential profitability as cost reduction potentials are oftentimes identified in ongoing product development.

\section{Discussion}

In this paper, the discussion is focused on a critical interpretation of the presented method itself. The key requirements specified in Section 2.1 are therefore chosen as a basis and deal as structure for the following investigation of the BiSA method. The main question to be answered can therefore be raised as follows: To which extent are the self-imposed goals of the developers achieved?

The general requirements have been set as consistency, comparability, reproducibility and falsifiability. Consistency of assessment systems is especially relevant with regard to system models. While the aim of the developers was to achieve full consistency of all aspects through the utilization of one system model, this could not be applied to the social function, as the building physical properties that provide the core of this aspect are not included in the life cycle inventory model that deals as a basis for the other aspects. Nevertheless, 5 out of 6 aspects could be modelled in a consistent way. Both comparability and reproducibility are met with the restriction of a not completely open model, which is caused by the fact that the underlying background databases are not publicly available. While consistency, comparability and reproducibility can be investigated on case study level, the falsifiability of sustainability in general is a critical requirement, as it simultaneously deals as a paradigm and as a scientific concept $[94,95]$. While the falsifiability of sustainability science and its scientific nature was questioned by Neumayer and Ziegler as well as Ott complemented the discourse and identified sustainability as a hybrid science that is falsifiable in the wider sense of conjecture and refutation [96]. In this sense, the presented framework offers a conjecture of BiSA open to refutation.

The basic requirements to decision support systems are met, even though their application has to prove true in future application. The proposed assessment system is able to support semi-structured and unstructured decisions and is applicable by decision makers throughout all phases of the decision making process. The requirements to sustainability assessment systems are classified based on the framework depicted in Figure 9 based on the experiences of previous applications. Overall, the assessment was developed by means of a comprehensive sustainability assessment with regard to the meta-assessment scheme, resulting in a classification of full strategicness, comprehensiveness and 
integratedness. A medium classification in terms of transparency, boundary-orientedness, scalability and stakeholders' involvement can be specified.

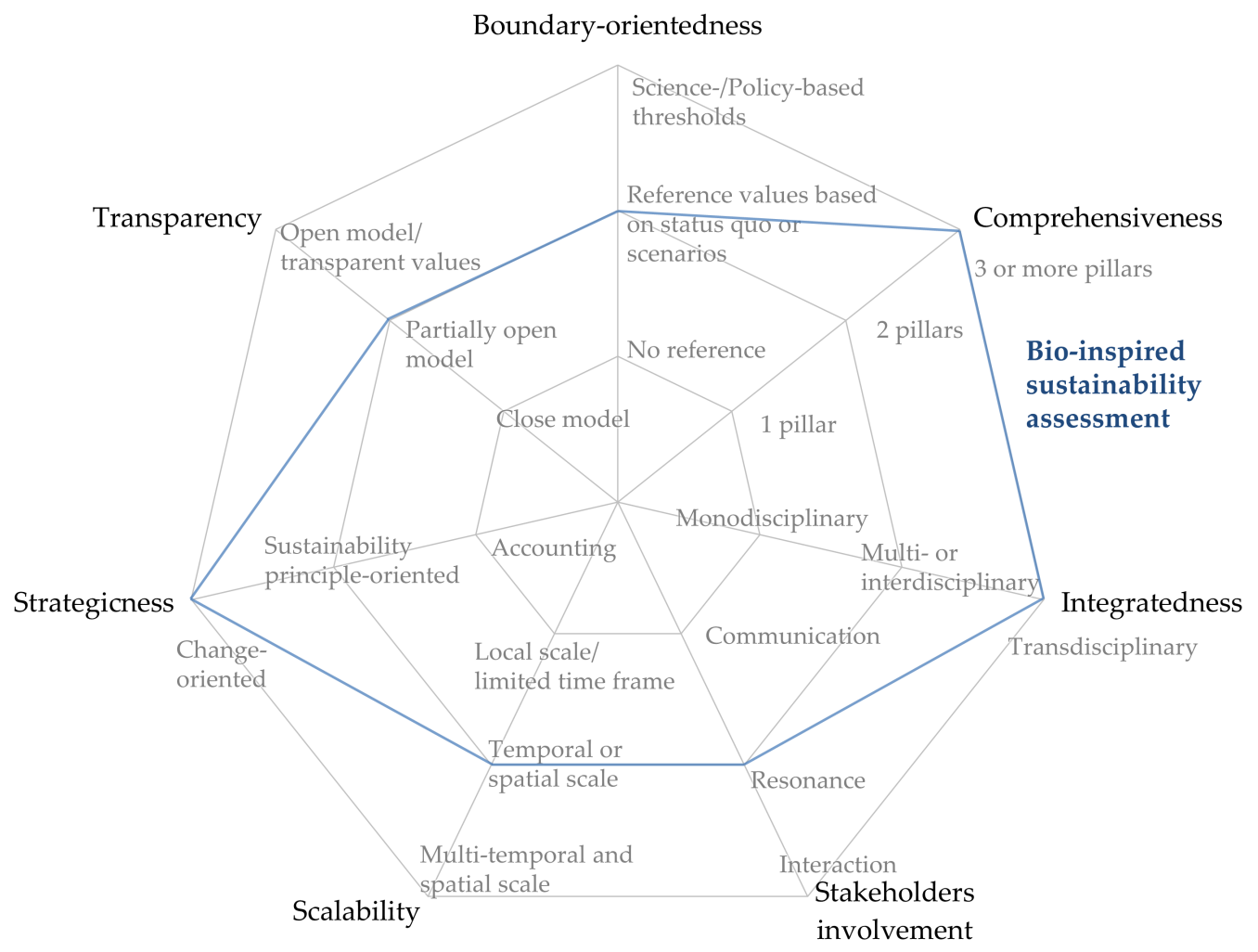

Figure 9. Classification of the BiSA based on the findings of the first applications (adapted from Sala et al. (2015), figure licensed under CC BY NC ND) [19].

The requirements of bio-inspired systems are mainly focusing on the practical application properties. Therefore, the meeting of the bio-inspired requirements can only be validated through ongoing application, including feedback of practitioners. Nevertheless, the general structure of the assessment system is designed to be applicable by developers effectively and it is planned to adapt the assessment structure based on the feedback of the practitioners. However, these specifications cannot be validated with the amount of studies available. The resilience has been investigated through performing sensitivity analyses and already gave a hint that the social burden assessment shows unintended changes and potentially low resilience with regard to modelling artifacts in the background database. As far as this can be identified by the assessing experts, the resulting distortions can be limited. In any case, this indicates further research demand in the field of social burden assessment based on the LCWE method.

\section{Conclusions}

The method of BiSA was presented in detail and applied to a first case study. The integration of bio-inspiration into sustainability and sustainability assessment proved to lead to new insights and a better connection to actual development processes. Furthermore, the connection of system properties derived from biology showed to provide improved access to the overall sustainability performance for practitioners. The results are depicted in a reduced approach, providing a single value for each aspect, including burdens and functions. However, several main points stay unresolved due to the limited amount of conducted studies so far. Since the project in which the evaluation was developed will be continued, an ongoing application of the assessment model is expected. Thereby, several key points will be investigated: 
- Are the bio-inspired requirements useful as criteria for meta-assessment and does the BiSA meet them?

- How could BiSA support the degree of target attainment in terms of developing sustainable solutions in the building sector?

- Is it possible to directly integrate further success principles of evolution (multifunctionality and change of function) in the assessment structure?

- Is it useful (or eligible) to determine the detailed structure or should the model itself be adaptive?

- Is it possible to fully address the meta-assessment classification requirements to sustainability assessments through further model development?

- Is it possible to gain a deeper understanding of the biological model systems in the framework of a further development of the BiSA?

Furthermore, a comprehensive investigation on the interaction of multifunctionality (both simultaneously and temporally separated) and resource demand will be performed. This will include the assessment of functionality as multidimensional set of functions and underlying properties enabling self-maintenance of living organisms making use of resources under environmental stress. The concept of bio-inspired sustainability provides a consistent framework including a sustainability model and a thereupon developed assessment system including all three dimensions of sustainability for both intended functions and unintended burdens. Its assessment is performed based on a consistent model on the basis of life cycle thinking and aims to reintegrate the principles of nonhuman biological systems into product development to purposefully develop sustainable solutions. While providing a first implementation, the model will be further developed towards a tool with a higher degree of automation and adapted in conventional, bio-inspired and biobased practical application.

Acknowledgments: The authors especially thank the German Research Foundation DFG for funding the CRC-Transregio 141 "Biological Design and Integrative Structures-Analysis, Simulation and Implementation in Architecture", in which the bio-inspired sustainability assessment has been developed. The co-author, H. Dahy developer of Bio-flexi, would like to thank the University of Stuttgart for the funded technology transfer project (HDF flexible BIO-Faserplatte), for the further development of the product and the Agency of Renewable Resources (FNR) under the German Ministry for Consumer Protection, Food and Agriculture (BMEL) for funding the project PLUS-funding number FKZ: 22008413 in which among others, upgrading systems for mass-production of NFRP have been developed. In addition, the authors thank the project partner companies Naftex $\mathrm{GmbH}$ - Germany where the extrusion took place, think-blue company-Germany for providing the extrusion tool and $\mathrm{K}$. Westermann $\mathrm{GmbH}+\mathrm{Co}$. KG Company-Germany for assisting in the veneering finishing of the Bio-flexi.

Author Contributions: Rafael Horn has developed the bio-inspired sustainability assessment and performed the assessment of the case study; Rafael Horn, Johannes Gantner and Philip Leistner have written and harmonized the assessment related chapters, Hanaa Dahy provided the information on Bio-flexi and wrote the technology-related application chapters, Olga Speck wrote the biology-related chapters and supported the assessment development with biological expertise.

Conflicts of Interest: The authors declare no conflict of interest.

\section{References}

1. Dickens, P. Reconstructing Nature: Alienation, Emancipation and the Division of Labour; Routledge: London, UK; New York, NY, USA, 1996.

2. Von Storch, H.; Stehr, N. Climate change in perspective. Nature 2000, 405, 615. [CrossRef] [PubMed]

3. Heidegger, M. The Question Concerning Technology; Garland Publishing: New York, NY, USA, 1977.

4. Cruzen, P.J. Geology of mankind: The Anthropocene. Nature 2002, 415, 23. [CrossRef] [PubMed]

5. Rockström, J.; Steffen, W.; Noone, K.; Persson, Å.; Chapin, F.S.I.; Lambin, E.; Lenton, T.M.; Scheffer, M.; Folke, C.; Schellnhuber, H.J.; et al. Planetary Boundaries: Exploring the Safe Operating Space for Humanity. Ecol. Soc. 2009, 14, 32. [CrossRef]

6. Von Carlowitz, H.C. Sylvicultura Oeconomica Oder Haußwirthliche Nachricht und Naturgemäßige Anweisung zur Wilden Baum-Zucht; Johan Friedrich Braun: Leipzig, Germany, 1713. 
7. Hawken, P.; Lovins, A.B.; Lovins, L.H. Natural Capitalism: Creating the Next Industrial Revolution, 1st ed.; Little, Brown and Co.: Boston, MA, USA, 1999.

8. Von Gleich, A. Das bionische Versprechen: Ist die Bionik so gut wie ihr Ruf? Ökologisches Wirtsch. 2007, 22, 21-23.

9. Reap, J.; Baumeister, D.; Bras, B. Holism, Biomimicry and Sustainable Engineering. In Energy Conversion and Resources; ASME: New York, NY, USA, 2005; pp. 423-431.

10. Horn, R.; Gantner, J.; Widmer, L.; Sedlbauer, K.P.; Speck, O. Bio-inspired Sustainability Assessment: A Conceptual Framework. In Biomimetic Research for Architecture and Building Construction: Biological Design and Integrative Structures; Knippers, J., Nickel, K.G., Speck, T., Eds.; Springer: Cham, Switzerland, 2016; Volume 8, pp. 361-377.

11. Speck, O.; Speck, D.; Horn, R.; Gantner, J.; Sedlbauer, K.P. Biomimetic bio-inspired biomorph sustainable? An attempt to classify and clarify biology-derived technical developments. Bioinspir. Biomim. 2017, 12, 11004.

12. Margulis, L.; Sagan, D.; Sagan, C. Life, Biology; Autopoietic Definition of Life; Encyclopædia Britannica, Inc.: Chicago, IL, USA, 2017; Available online: https:/ /www.britannica.com/topic/life\#ref1014068 (accessed on 3 November 2017).

13. Varela, F.G.; Maturana, H.R.; Uribe, R. Autopoiesis: The organization of living systems, its characterization and a model. Biosystems 1974, 5, 187-196. [CrossRef]

14. Popper, K.R. Logik der Forschung, 11th ed.; Mohr Siebeck: Tübingen, Germany, 2005.

15. Parker, C. An approach to requirements analysis for decision support systems. Int. J. Hum. Comput. Stud. 2001, 55, 423-433. [CrossRef]

16. Steele, K.; Stefánsson, H.O. Decision Theory. In The Stanford Encyclopedia of Philosophy, 2016th ed.; Zalta, E.N., Ed.; Metaphysics Research Lab., Stanford University: Stanford, CA, USA, 2016.

17. Sprague, R.H. A Framework for the Development of Decision Support Systems. MIS Q. 1980, 4, 1-26. [CrossRef]

18. Sala, S.; Farioli, F.; Zamagni, A. Life cycle sustainability assessment in the context of sustainability science progress (part 2). Int. J. Life Cycle Assess. 2013, 18, 1686-1697. [CrossRef]

19. Sala, S.; Ciuffo, B.; Nijkamp, P. A systemic framework for sustainability assessment. Ecol. Econ. 2015, 119, 314-325. [CrossRef]

20. Finkbeiner, M.; Schau, E.M.; Lehmann, A.; Traverso, M. Towards Life Cycle Sustainability Assessment. Sustainability 2010, 2, 3309-3322. [CrossRef]

21. UNEP/SETAC Life Cycle Initiative. Towards a Life Cycle Sustainability Assessment: Making Informed Choices on Products; United Nations Environment Programme: Nairobi, Kenya, 2011.

22. Kloepffer, W. Life cycle sustainability assessment of products. Int. J. Life Cycle Assess. 2008, 13, 89-95. [CrossRef]

23. Sala, S.; Farioli, F.; Zamagni, A. Progress in sustainability science: Lessons learnt from current methodologies for sustainability assessment: Part 1. Int. J. Life Cycle Assess. 2013, 18, 1653-1672. [CrossRef]

24. Folke, C.; Carpenter, S.; Elmqvist, T.; Gunderson, L.; Holling, C.S.; Walker, B. Resilience and Sustainable Development: Building Adaptive Capacity in a World of Transformations. AMBIO J. Hum. Environ. 2002, 31, 437-440. [CrossRef]

25. Moore, F.C. Toppling the Tripod: Sustainable Development, Constructive Ambiguity and the Environmental Challenge. Cons. J. Sustain. Dev. 2011, 1, 141-150.

26. World Commission on Environment and Development. Report of the World Commission on Environment and Development: Our Common Future; Oxford University Press: Oxford, UK, 1987; Available online: http: / / www.un-documents.net/our-common-future.pdf (accessed on 3 January 2018).

27. Zamagni, A.; Pesonen, H.-L.; Swarr, T. From LCA to Life Cycle Sustainability Assessment: Concept, practice and future directions. Int. J. Life Cycle Assess. 2013, 18, 1637-1641. [CrossRef]

28. Parent, J.; Cucuzzella, C.; Revéret, J.-P. Revisiting the role of LCA and SLCA in the transition towards sustainable production and consumption. Int. J. Life Cycle Assess. 2013, 18, 1642-1652. [CrossRef]

29. Braungart, M.; McDonough, W. Cradle to Cradle: Einfach Intelligent Produzieren; Piper: München, Germany; Zürich, Switzerland, 2014. 
30. Bjørn, A.; Hauschild, M.Z. Cradle to Cradle and LCA-Is there a Conflict? In Glocalized Solutions for Sustainability in Manufacturing, Proceedings of the 18th CIRP International Conference on Life Cycle Engineering, Technische Universität Braunschweig, Braunschweig, Germany, 2-4 May 2011; Hesselbach, J., Herrmann, C., Eds.; Springer: Berlin/Heidelberg, Germany, 2011; pp. 599-604.

31. Onat, N.C.; Kucukvar, M.; Tatari, O. Integrating triple bottom line input-output analysis into life cycle sustainability assessment framework: The case for US buildings. Int. J. Life Cycle Assess. 2014, 19, 1488-1505. [CrossRef]

32. Hacking, T.; Guthrie, P. A framework for clarifying the meaning of Triple Bottom-Line, Integrated, and Sustainability Assessment. Environ. Impact Assess. Rev. 2008, 28, 73-89. [CrossRef]

33. Onat, N.; Kucukvar, M.; Halog, A.; Cloutier, S. Systems Thinking for Life Cycle Sustainability Assessment: A Review of Recent Developments, Applications, and Future Perspectives. Sustainability 2017, 9, 706. [CrossRef]

34. Petti, L.; Serreli, M.; Di Cesare, S. Systematic literature review in social life cycle assessment. Int. J. Life Cycle Assess. 2016, 18, 1549. [CrossRef]

35. Guinée, J. Life Cycle Sustainability Assessment: What Is It and What Are Its Challenges? In Taking Stock of Industrial Ecology; Clift, R., Druckman, A., Eds.; Springer International Publishing: Cham, Switzerland, 2016; pp. $45-68$.

36. Von Gleich, A.; Pade, C.; Petschow, U.; Pissarskoi, E. Bionik: Aktuelle Trends und Zukünftige Potenziale; Institut für ökologische Wirtschaftsforschung: Berlin, Germany, 2007.

37. Frey, E.; Masselter, T.; Speck, T. Was ist bionisch? Eine Anal. Ideenflusses Biol. Tech. Naturwissensch. Rundsch. 2011, 64, 117-126.

38. Coineau, Y.; Kresling, B. Erfindungen der Natur; Tessloff: Nürnberg, Germany, 1989.

39. Barthlott, W.; Neinhuis, C. Purity of the sacred lotus, or escape from contamination in biological surfaces. Planta 1997, 202, 1-8. [CrossRef]

40. Lienhard, J.; Schleicher, S.; Poppinga, S.; Masselter, T.; Milwich, M.; Speck, T.; Knippers, J. Flectofin: A hingeless flapping mechanism inspired by nature. Bioinspir. Biomim. 2011, 6, 45001. [CrossRef] [PubMed]

41. Walsh, D.M. Fitness and Function. Br. J. Philos. Sci. 1996, 47, 553-574. [CrossRef]

42. Achinstein, P. Function Statements. Philos. Sci. 1977, 44, 341-367. [CrossRef]

43. Verein Deutscher Ingenieure VDI 6223/1. Bionik: Bionische Materialien, Strukturen und Bauteile; Biomimetics: Biomimetic Materials, Structures and Components VDI 6223 (Berlin: Beuth); Beuth: Berlin, Germany, 2013.

44. Lexikon der Biologie. "Ressourcen"; Spektrum Akademischer Verlag: Heidelberg, Germany, 1999; Available online: http:/ / www.spektrum.de/lexikon/biologie/ressourcen/56391 (accessed on 29 November 2017).

45. Antony, F.; Grießhammer, R.; Speck, T.; Speck, O. Natur-(k)ein Vorbild für nachhaltige Entwicklung. In Bionik: Patente aus der Natur; Kesel, A., Zehren, D., Eds.; Meiners-Druck: Bremen, Germany, 2013; pp. 164-170.

46. Speck, O. Das bionische Versprechen: Ein Beitrag zur Bildung für nachhaltige Entwicklung. In Bionik: Patente aus der Natur; Kesel, A., Zehren, D., Eds.; Meiners-Druck: Bremen, Germany, 2015; pp. 135-146.

47. Walsh, D.M. Teleology. In The Oxford handbook of Philosophy of Biology, 1st ed.; Ruse, M., Ed.; Oxford University Press: Oxford, UK, 2010; pp. 113-137.

48. Huiskes, R. If bone is the answer, then what is the question? J. Anat. 2000, 197, 145-156. [CrossRef] [PubMed]

49. Sureau, S.; Mazijn, B.; Garrido, S.R.; Achten, W.M.J. Social life-cycle assessment frameworks: A review of criteria and indicators proposed to assess social and socioeconomic impacts. Int. J. Life Cycle Assess. 2017, 30, 181. [CrossRef]

50. Benoît, C.; Mazijn, B. Guidelines for Social Life Cycle Assessment of Products; United Nations Environment Programme: Nairobi, Kenya, 2009.

51. Jørgensen, A. Social LCA-A way ahead? Int. J. Life Cycle Assess. 2013, 18, 296-299. [CrossRef]

52. Moosbrugger, V. Das große Sterben vor 65 Millionen Jahren. In Katastrophen in der Erdgeschichte-Wendezeiten des Lebens; Hansch, W., Ed.; Städtische Museen: Heilbronn, Germany, 2003; pp. 144-153.

53. International Organization for Standardization. Umweltmanagement-Ökobilanz-Grundsätze und Rahmenbedingungen (ISO 14040:2006); Beuth: Berlin, Germany, 2009.

54. International Organization for Standardization. Umweltmanagement-Ökobilanz-Anforderungen und Anleitungen (ISO 14044:2006): Environmental Management_Life Cycle Assessment-Requirements and Guidelines, 1st ed.; Beuth: Berlin, Germany, 2009. 
55. International Reference Life Cycle Data System (ILCD). ILCD Handbook—General Guide on LCA—Provisons and Action Steps/General Guide for Life Cycle Assessment: Provisions and Action Steps; Publications Office: Luxembourg, 2010.

56. Thinkstep, A.G. GaBi TS: Sofware-System and Databases for Life Cycle Engineering; Thinkstep AG: Leinfelden-Echterdingen, Germany, 2017.

57. Steffen, W.; Richardson, K.; Rockstrom, J.; Cornell, S.E.; Fetzer, I.; Bennett, E.M.; Biggs, R.; Carpenter, S.R.; de Vries, W.; Wit, C.A.D.; et al. Planetary boundaries: Guiding human development on a changing planet. Science 2015, 347, 1259855. [CrossRef] [PubMed]

58. Ryberg, M.W.; Owsianiak, M.; Richardson, K.; Hauschild, M.Z. Challenges in implementing a Planetary Boundaries based Life-Cycle Impact Assessment methodology. J. Clean. Prod. 2016, 139, 450-459. [CrossRef]

59. Sala, S.; Benini, L.; Crenna, E.; Secchi, M. Global Environmental Impacts and Planetary Boundaries in LCA: Data Sources and Methodological Choices for the Calculation of Global and Consumption-Based Normalisation Factors; European Commission: Brussels, Belgium, 2016.

60. Sandin, G.; Peters, G.M.; Svanström, M. Using the planetary boundaries framework for setting impact-reduction targets in LCA contexts. Int. J. Life Cycle Assess. 2015, 20, 1684-1700. [CrossRef]

61. Bjørn, A.; Hauschild, M. Integrating Planetary Boundaries into the Life Cycle Assessment Framework for Assessing Absolute Environmental Sustainability of Products and Systems. In Proceedings of the Third International Resilience Science and Policy Conference, Montpellier, France, 5-9 May 2014.

62. Rockström, J.; Steffen, W.; Noone, K.; Persson, A.; Chapin, F.S.; Lambin, E.F.; Lenton, T.M.; Scheffer, M.; Folke, C.; Schellnhuber, H.J.; et al. A safe operating space for humanity. Nature 2009, 461, 472-475. [CrossRef] [PubMed]

63. Pizzol, M.; Laurent, A.; Sala, S.; Weidema, B.; Verones, F.; Koffler, C. Normalisation and weighting in life cycle assessment: Quo vadis? Int. J. Life Cycle Assess. 2017, 22, 853-866. [CrossRef]

64. Vidal Legaz, B.; Maia De Souza, D.; Teixeira, R.; Antón, A.; Putman, B.; Sala, S. Soil quality, properties, and functions in life cycle assessment: An evaluation of models. J. Clean. Prod. 2017, 140, 502-515. [CrossRef]

65. Schneider, L.; Berger, M.; Finkbeiner, M. Abiotic resource depletion in LCA-Background and update of the anthropogenic stock extended abiotic depletion potential (AADP) model. Int. J. Life Cycle Assess. 2015, 20, 709-721. [CrossRef]

66. Klinglmair, M.; Sala, S.; Brandão, M. Assessing resource depletion in LCA: A review of methods and methodological issues. Int. J. Life Cycle Assess. 2014, 19, 580-592. [CrossRef]

67. Bos, U.; Horn, R.; Beck, T.; Lindner, J.P.; Fischer, M. LANCA—Characterization Factors for Life Cycle Impact Assessment: Version 2.0; Fraunhofer Verlag: Stuttgart, Germany, 2016.

68. Swarr, T.E.; Hunkeler, D.; Klöpffer, W.; Pesonen, H.-L.; Ciroth, A.; Brent, A.C.; Pagan, R. Environmental life-cycle costing: a code of practice. Int. J. Life Cycle Assess. 2011, 16, 389-391. [CrossRef]

69. Eurostat. Statistics on Industrial Production and International Trade (Prom), Annual Detailed Data by Prodcom List (According to NACE); Eurostat: Luxembourg, 2016; Available online: http:/ / epp.eurostat.ec.europa.eu/ newxtweb / (accessed on 24 October 2017).

70. Callejas, D.G. Biology and Economics: Metaphors that Economists usually take from Biology. Ecos Econ. 2007, 11, 153-164.

71. Jørgensen, A.; Le Bocq, A.; Nazarkina, L.; Hauschild, M. Methodologies for social life cycle assessment. Int. J. Life Cycle Assess. 2008, 13, 96-103. [CrossRef]

72. Sala, S.; Vasta, A.; Mancini, L.; Dewulf, J.; Rosenbaum, E. Social Life Cycle Assessment: State of the Art and Challenges for Product Policy Support; Publications Office: Luxembourg, 2015.

73. Chhipi-Shrestha, G.K.; Hewage, K.; Sadiq, R. 'Socializing' sustainability: A critical review on current development status of social life cycle impact assessment method. Clean Technol. Environ Policy 2015, 17, 579-596. [CrossRef]

74. Iofrida, N.; de Luca, A.I.; Strano, A.; Gulisano, G. Can social research paradigms justify the diversity of approaches to social life cycle assessment? Int. J. Life Cycle Assess. 2016, 20, 498. [CrossRef]

75. Okasha, S. Biological Altruism. In The Stanford Encyclopedia of Philosophy, 2013rd ed.; Zalta, E.N., Ed.; Metaphysics Research Lab., Stanford University: Stanford, CA, USA, 2013.

76. Auletta, G.; Leclerc, M.; Martínez, R.A. (Eds.) Biological Evolution: Facts and Theories: A Critical Appraisal 150 Years after "The Origin of Species". In Proceedings of the 3rd ICSD International Conference, Rome, Italy, 3-7 March 2009; Gregorian \& Biblical Press: Roma, Italy, 2011. 
77. Alexander, R. Biology and the moral paradoxes. J. Soc. Biol. Syst. 1982, 5, 389-395. [CrossRef]

78. FitzPatrick, W. Morality and Evolutionary Biology. In The Stanford Encyclopedia of Philosophy; Stanford University: Stanford, CA, USA, 2016.

79. Sen, A. Development as Freedom, 1st ed.; Knopf: New York, NY, USA, 2001.

80. Fantke, P.; Bijster, M.; Hauschild, M.Z.; Huijbregts, M.; Jolliet, O.; Kounina, A.; Magaud, V.; Margni, M.; McKone, T.E.; Rosenbaum, R.K.; et al. USEtox ${ }^{\circledR} 2.0$ Documentation (Version 1.00); USEtox®Team: Bordeaux, France, 2017.

81. Alkire, S. Dimensions of Human Development. World Dev. 2002, 30, 181-205. [CrossRef]

82. Aulisio, D. All SHDB Tables, Indicators, Characterizations-Update; Social Hotspots Database; York, ME, USA, 2013. Available online: http:/ / socialhotspot.org/wp-content/uploads/2013/03/All-SHDB-Tables-IndicatorsCharacterizations-UPDATE.pdf (accessed on 8 January 2018).

83. Barthel, L.-P. Methode zur Abschätzung Sozialer Aspekte in Lebenszyklusuntersuchungen auf Basis Statistischer Daten; Fraunhofer Verlag: Stuttgart, Germany, 2015.

84. Albrecht, S.; Endres, H.-J.; Knüpffer, E.; Spierling, S. Biokunststoffe-Quo vadis? UmweltWirtschaftsForum 2016, 24, 55-62. [CrossRef]

85. Gantner, J.; Beck, T.; Horn, R. CommONEnergy Deliverable 5.7: Social Impact Assessment of Shopping Mall Retrofitting; European Commission: Brussels, Belgium, 2017.

86. Reitinger, C.; Dumke, M.; Barosevcic, M.; Hillerbrand, R. A conceptual framework for impact assessment within SLCA. Int. J. Life Cycle Assess. 2011, 16, 380-388. [CrossRef]

87. Buller, D.J. (Ed.) Function, Selection and Design; State University of New York Press: Albany, NY, USA, 1999.

88. Verein Deutscher Ingenieure VDI 6220/1. Bionik-Konzeption und Strategie-Abgrenzung Zwischen Bionischen und Konventionellen Verfahren/Produkten; Biomimetics-Conception and Strategy-Differences between Biomimetic and Conventional Methods/Products; ICS 07.080; Beuth: Berlin, Germany, 2012.

89. Moro, J.L. Baukonstruktion: Vom Prinzip zum Detail; Springer: Berlin, Germany, 2009.

90. Dahy, H.; Knippers, J. Flexible High-Density Fiberboard and Method for Manufacturing the Same. EP3166765A1; Filed 8. July 2014, Published 13 January 2016. Based on Same Patent, Also Applied as WO2016005026A1; CN106604806A; US20170144327, EP2965882 A1. Available online: https:/ / patentscope. wipo.int/search/en/detail.jsf?docId=WO2016005026 (accessed on 8 January 2018).

91. Dahy, H. Biocomposite materials based on annual natural fibres and biopolymers-Design, fabrication and customized applications in architecture. J. Constr. Build. Mater. 2017, 147, 212-220. [CrossRef]

92. Dahy, H. Agro-Fibres Biocomposites Applications and Design Potentials in Contemporary Architecture: Case Study: Rice Straw Biocomposites; Forschungsbericht Nr. 38; Universität Stuttgart: Stuttgart, Germany, 2015. Available online: http:/ / dx.doi.org/10.18419/opus-113 (accesses on 8 January 2018).

93. Deutsches Institut für Normung e. V. DIN EN 15978. Nachhaltigkeit von Bauwerken-Bewertung der Umweltbezogenen Qualität von Gebäuden-Berechnungsmethode; Deutsche Fassung EN 15978-2011; Beuth: Berlin, Germany, 2012.

94. Kuhn, T.S. The Structure of Scientific Revolutions, 2nd ed.; University of Chicago Press: Chicago, IL, USA, 1970.

95. Ziegler, R.; Ott, K. The quality of sustainability science: A philosophical perspective. Sustain. Sci. Pract. Policy 2017, 7, 31-44.

96. Dietz, S.; Neumayer, E. Weak and strong sustainability in the SEEA: Concepts and measurement. Ecol. Econ. 2007, 61, 617-626. [CrossRef]

(C) 2018 by the authors. Licensee MDPI, Basel, Switzerland. This article is an open access article distributed under the terms and conditions of the Creative Commons Attribution (CC BY) license (http:/ / creativecommons.org/licenses/by/4.0/). 